\title{
The role of microRNA in metastatic processes of non-small cell lung carcinoma
}

\author{
Zuzana Pastorkova ${ }^{a}$, Jozef Skarda ${ }^{a}$, Jozef Andel ${ }^{b}$
}

\begin{abstract}
Background. MicroRNAs are small non-coding one-stranded RNA molecules that play an important role in the posttranscriptional regulation of genes. Bioinformatic predictions indicate that each miRNA can regulate hundreds of target genes. MicroRNA expression can be associated with various cellular processes leading to the metastasis of malignant tumours including non-small cell lung carcinoma. This review summarizes current knowledge on the role of microRNAs in NSCLC metastasis to the brain and lymph nodes.

Methods. A search of the NCBI/PubMed database for publications on expression levels and the mechanisms of microRNA action in NSCLC metastasis.

Results and Conclusion. Dysregulation of microRNAs in NSCLC can be associated with brain and lymph node metastasis. There are differences in microRNA expression profiling between NSCLC with and without metastases but it is currently not possible to reliably predict the site of metastasis in NSCLC. Based on data from RNAmicroarrays, bioinformatics analysis is able to predict the target genes of highlighted microRNAs, providing us with complex information about cancer cell features such as enhanced proliferation, migration and invasion. Such microRNAs may then be knocked-down using siRNAs or substituted with miRNA mimics. RNA microarray profiling may thus be a useful tool to select up- or down-regulated microRNAs. A number of authors suggest that microRNAs could serve as biomarkers and therapeutic targets in the treatment of NSCLC metastasis.
\end{abstract}

Key words: microRNA, non-small cell lung carcinoma, brain metastasis, lymph node metastasis

Received: November 3, 2015; Accepted with revision: April 8, 2016; Available online: April 20, 2016 http://dx.doi.org/10.5507/bp.2016.021

${ }^{a}$ Department of Clinical and Molecular Pathology, Faculty of Medicine and Dentistry, Palacky University Olomouc, Czech Republic ${ }^{b}$ Department of Oncology, Faculty of Medicine and Dentistry, Palacky University Olomouc, Czech Republic Corresponding author: Jozef Skarda, e-mail:jojos@email.cz

\section{INTRODUCTION}

Lung cancer is one of the most freequently diagnosed malignant tumours in developing and developed countries and the leading cause of cancer-related mortality worldwide $^{1}$. Non-small cell lung cancers (NSCLC) account for approximately $80 \%$ of all cases of lung cancers and have a 5 -year survival rate of only $16 \%$ (ref. $^{2}$ ) and almost $2 / 3$ of patients with NSCLC are diagnosed at an advanced stage of disease ${ }^{3} .25 \%$ of non-small cell lung cancers metastasize to brain ${ }^{4}$. For this reason, predicting the metastatic potential of primary tumours is of paramount importance in providing potential prophylactic therapy.

In spite of ongoing research, there are currently no reliable biomarkers for predicting metastatic spread to different sites. One of the best candidates for this purpose are microRNAs since they are differentially expressed in different tissues.

MicroRNAs are small noncoding molecules of 19-24 nucleotides in length ${ }^{5}$. About $1 / 3$ of human genes are mediated by miRNAs which negatively regulate gene expression by interferring with mRNA translation ${ }^{6,7}$. Increasing evidence indicates that miRNAs may be a key player in the regulation of tumour cell invasion and metastasis in a variety of human cancers including NSCLC $\left(\right.$ ref. $\left.^{8}\right)$. Nearly $50 \%$ of microRNAs are located in fragile regions of the human genome'. Each miRNA has many target genes within pathways, while several miRNAs can regulate the same gene ${ }^{10,11}$. Some microRNAs can regulate oncogenes/ tumour suppr essors as wel1 ${ }^{12,13}$. Some are differentially expressed in histological subtypes of cancers suggesting a dual function ${ }^{14}$. MiRNAs are ubiquitously deregulated in all kinds of cancers. By modulating either multiple targets or entire pathways, and by having unique expression profiles and greater stability in biological samples, miRNAs have quickly gained diagnostic and therapeutic value ${ }^{15}$.

The current review summarizes the potential role of selected miRNAs in the process of tumour spread to different sites and highlights future perspectives on verifying the role of different miRNAs in the process of tumour progression.

\section{The role of miRNAs in brain metastasis}

Few miRNAs have been studied in association with brain metastasis so far.

Western blot and RT-qPCR analyses (Hwang et al. ${ }^{16}$ ) showed that brain metastatic PC14PE6/LvBr4 cells had mesenchymal characteristics and higher invasiveness than PC14PE6 cells. These authors also found that miR-95$3 p$ was down-regulated, cyclin D1 was up- regulated and actin binding LIM protein family member 2 (ABLIM2) was reduced in PC14PE6/LvBr4 cells. ABLIM2 is closely associated with cytoskeletal organization and biogenesis 
and is the host gene of miR-95. MiR-95-3p suppressed cyclin D1 expression through direct binding to 3' UTR its mRNA and suppressed the invasiveness and proliferation of PC14PE6/LvBr4 cells. PE14PE6/LvBr4 cells showed decreased E-cadherin expression and N-cadherin upregulation, indicating that PE14PE6/ LvBr4 cells underwent EMT. Consistent with in vitro metastatic cells, the levels of miR-95-3p and ABLIM2 mRNA were decreased in brain metastatic tissues compared to lung cancer tissues, and higher cyclin D1 expression was connected to poor prognosis.

Surgical specimens and clinical records were obtained from 25 lung adenocarcinoma patients who had undergone surgical removal of primary tumours $(\mathrm{N}=11)$ or brain metastases $(\mathrm{N}=14)\left(\right.$ ref. $\left.^{16}\right)$. Since actin binding proteins are of importance in actin polymerization and are dynamically controlled during metastatic processes, Hwang et al. suggest that downregulation of ABLIM2 is closely related to the cytoskeletal organization of cancer cells ${ }^{16}$.

Cyclin D1 is an oncogene frequently over-expressed in various cancers including lung cancer ${ }^{17-20}$. Cyclin D1 plays a key role in processes leading to acquisition of metastatic potential such as migratory and invasive properties ${ }^{16}$. Over-expression of cyclin D1 in glioma cells increases matrix metalloproteinase (MMP) activity and cellular motility $^{21}$. Cyclin D1 is also down-regulated by miR-545 in lung cancer tissues compared to adjacent normal tissues and inhibits proliferation in vivo and in vitro ${ }^{22}$. Cyclin D1 is a key regulator of the cell cycle progression from the G1 phase to the $\mathrm{S}$ phase and is suspected to have an important role in the process of carcinogenesis and cancer progression $^{23}$. Macrophages, fibroblasts, and epithelial cells have, after depletion of cyclin D1, enhanced adhesion and reduced migration ${ }^{24-26}$, a process essential for metastasis. Cyclin D1 protein levels are induced by $\beta$-catenin overexpression and reduced in cells overexpressing the cadherin cytoplasmic domain. Increased $\beta$-catenin levels may thus promote neoplastic conversion by triggering cyclin D1 gene expression and consequently, uncontrolled progression into the cell cycle ${ }^{27}$.

Chen et al. compared NSCLC tissues with brain metastasis (BM) to NSCLC tissues without BM and provided evidence that miR-378 overexpression is associated with NSCLC brain metastasis by promoting cell migration, invasion and tumour angiogenesis. Detailed investigation of the human NSCLC cell line A549 revealed that miR378 promotes these properties by up-regulation of VEGF, MMP-2 and MMP-9, the key metalloproteinases involved in angiogenesis and blood vessel invasion though the extracellular matrix ${ }^{28}$. Hua, et al. demonstrated that miR-378 binds to VEGF 3 ' UTR competing with miR-125a for the same seed region and promotes VEGF expression in a model of human nasopharyngeal carcinoma cells ${ }^{29}$.

Arora et al. demonstrated that miR-330-3p expression was increased in NSCLC patient tissues and was involved in NSCLC brain metastasis ${ }^{30}$. Liu et al. reported that miR-330-3p is up-regulated in NSCLC patient tissues compared to normal adjacent tissues. These authors carried out in vitro studies proving that over-expression of
miR-330-3p significantly enhanced cell proliferation in A549 and H23 cells transfected with miR-330-3p mimics compared to control miRNA mimic transfected cells. MiR-330-3p over-expression resulted in fewer cells in the G0/G1 phase and more cells in the G2/M and S phase. Their data also showed that the early growth response protein 2 (EGR2) expression level was decreased in miR330-3p overexpressing cells compared to control cells. Moreover, EGR2 knockdown significantly increased cell proliferation. Taken together, the results of these authors show that EGR2 is a target of miR-330-3p (ref. ${ }^{31}$ ).

Unoki and Nakamura suggest that EGR2 is able to suppress growth in a variety of cancer cells significantly by mediating the PTEN signalling pathway ${ }^{32}$.

The results of the experiments of Remon et al. revealed three microRNAs involved in NSCLC brain metastasis. These are miR-197, miR-184 and miR-423-5p over-expressed in NSCLC BM+ patients compared to a control group of NSCLC BM- patients ${ }^{33}$. MiRNA-197 overexpression is a potential biomarker for early detection of lung cancers and also correlates with metastasis ${ }^{34}$. Elevated miR-197 expression is correlated with reduced Fus 1 expression in NSCLC tumour, confirming that miR-197 targets the 3 ' UTR of the Fus 1 transcript ${ }^{35}$ and with reduced p53 tumour suppressor gene ${ }^{36}$. FUS1 induces apoptosis through the activation of the intrinsic mitochondrial-dependent and Apaf-1-associated pathways and inhibits the function of protein tyrosine kinases including EGFR and AKT among others, in lung cancer ${ }^{37}$. Inhibition of miR-197 promotes upregulation of $\mathrm{p} 53$-dependent apoptosis in lung cancers ${ }^{36}$. MiR-184 suppresses cell proliferation by modulating cell cycle transition signals such as C-Myc, blocking cell growth mediated by PI3K/AKT/C-Jun pathway. MiR-184 is positively modulated by CCDC19 in NSCLC (ref. ${ }^{38}$ ). These results are with accordance with an experiment on hepatocellular carcinoma where miR-184 overexpression increased cell proliferation, tumourigenicity and cell cycle progression. SOX7 was identified as a direct target of miR-184. The interaction led to downregulation of the SOX7 protein $^{39}$. SOX7 was found to be down-regulated in lung cancer ${ }^{40}$. This protein together with SOX17 and SOX18 mediates various developmental processes and tumourigenesis ${ }^{41}$. SOX7 is a transcription factor that binds to $\beta$-catenin and negatively regulates its activity ${ }^{42}$. MiR-423-5p has been found to be related to cell proliferation and invasion in gastric cancer cells ${ }^{43}$. There are no data describing miR423-5p in lung cancers.

Microarray analysis of 5 primary and 3 brain metastatic lung adenocarcinoma samples performed by Zhao et al. showed five upregulated microRNAs: miR-9*, miR1471, miR-718, miR-3656, miR-720 and 3 down-regulated microRNAs: miR-214, miR-145, miR-23a. The most significantly deregulated microRNAs: miR-145, miR-214 and miR-1471 were subsequently validated in an additional 35 primary and 8 BM lung adenocarcinoma samples using TaqMan quantitative PCR. Taken together these authors used 51 samples. 40 primary lung adenocarcinoma samples (20 samples with lymph node metastasis, 20 samples without) and $11 \mathrm{BM}$ from lung adenocarcinoma. Using 
functional assay Zhao et al. found that the expression of miR-145 can regulate the proliferation ability of A549 and SPC-A1 cells in vitro and is related to lymph node metastasis, migration and invasion. These results suggest that miR-145 may have a cell type specific function and play an important role in the process of BM in lung adenocarcinoma $^{44}$. Previous studies indicate that miR-145 acts as a metastasis suppressor, is down-regulated in NSCLC cells and has more direct targets. MiR-145 acts as tumour suppressor, inhibiting migration and invasion via inhibition of fascin 1 protein expression in NSCLC cells ${ }^{45}$. The motility and invasiveness of human cancers can be associated with complex rearrangements of the actin cytoskeleton that are governed by several actin binding proteins. One actin-binding protein that has been linked to the invasive behaviour of carcinomas is fascin which serves to aggregate $\mathrm{F}$ actin into bundles ${ }^{46}$. FSCN1 thus contributes to cell interactions, migration, intracellular movements, motility and cell invasion ${ }^{47}$. Ye et al. showed that low miR145 silenced by DNA methylation promotes NSCLC cell proliferation, migration and invasion by targeting mucin 1 $\left(\right.$ ref. $\left.^{48}\right)$. Mucin 1 is a heterodimeric protein that regulates critical pathways in oncogenesis including cell proliferation, self-renewal, tissue invasion, and apoptosis ${ }^{49}$. HsamiR-145 targets EGFR and nucleoside diphosphate linked moiety X-type motif 1 (NUDT1) in lung adenocarinoma cells. The expression of EGFR and NUDT1 was significantly down-regulated after miR-145 transfection in human lung adenocarcinoma cells ${ }^{50}$. The role of NUDT1, also known as MTH1, is to hydrolyze 8-oxo-dGTP to the monophosphate form ${ }^{51}$. 8-oxo-dGTP is highly mutagenic, altered by oxidative stress and one of the main endogenous sources for spontaneous mutagenesis ${ }^{52}$. The induction of NUDT1 expression has been linked to oxidative stess and cellular proliferation and persistent oxidative stress in cancer cells may stimulate cellular proliferation ${ }^{53}$. NUDT1 has been shown to be over-expressed in various human tumours including lung cancer ${ }^{53-56}$. Huber et al. deduced that since NUDT1 is thought to prevent incorporation of oxidized nucleaotides into DNA, inhibitors of NUDT1 should increase the content of genomic 8-oxodGTP and thus induce DNA damage in cancer cells ${ }^{57}$. MiR-145 may be thus of importance in cancer treatment.

Arora and colleges performed microarray profiling on samples of clinically matched NSCLC from seven patients with brain metastasis and six without brain metastasis. Statistical analysis and qRT-PCR validation confirmed eight microRNAs to be significantly differentially expressed. Of these, miR-328 and miR-330-3p were able to correctly classify BM+ versus BM- patients. In vitro studies carried out on A549 cell line showed that A549 that over-expressed miR-328, had several signalling pathways affected such as interleukin-1 (IL-1) signalling, VEGF signalling, and PDGF signalling. VEGF/IL1 signalling pathway, and several of the miR-328 target genes play a key role in controlling this signalling pathway leading to loss of cell adhesion and increased migration. These target genes include PRKCA, VEGFD, NOTCH1, IL1alpha, IL1-beta, and PLC-gamma among others. PRKCA (protein kinase $\mathrm{C}$, alpha), which was one of the genes up-regulated in A549-328 cells, was also over-expressed at the protein level in A549-328 cells compared to A549empty cells. Moreover, A549-328 cells had significantly increased cell migration compared to A549 cells which were significantly reduced after PRKCA knockdown ${ }^{30}$. IL1-beta via PRKCA induces the expression of UPA (urokinase plasminogen activator), which leads to migration of A549 NSCLC cells ${ }^{58}$. uPA is a plasminogen activator, one of the serine proteases originally described as matrixand fibrin-degrading enzymes. The expression of such proteases is strictly regulated and involved in physiological and pathological processes such as cancer invasion and metastasis ${ }^{59}$. Notch signalling, comprised of four receptor isoforms (Notch1, Notch2, Notch3, Notch4) and five ligands members (Delta-like 1, Delta-like 3, Delta-like 4, Jagged-1 and Jagged-2), is crucial for cell proliferation, differentiation and apoptosis ${ }^{60}$. Deregulated Notch signalling leads to various diseases, such as T cell leukemia and lung cancer $^{61,62}$. VEGF expression in lung cancer cells could be attributed to increased activity of the JAK/STAT3 signalling pathway which is associated with decreased survival rate $^{63}$. Overexpression of VEGF in NSCLC may predict poor prognosis ${ }^{64}$. PLC-gamma has been found to be connected to tumour cell motility required for invasiveness and metastasis ${ }^{65}$. Activation of this protein lies upstream of cytoskeletal reorganization. PLC $\gamma$ is at the convergence point of various signalling pathways leading to spreading and motility ${ }^{66}$.

\section{MiRNAs involved in lymph node metastasis}

An example of a microRNA involved in lymph node metastasis is cited by Meng et al. who claim that miR-31 is upregulated in lung adenocarcinoma tissues from patients with lymph node metastases compared with those without lymph node metastases. In vitro assay on human lung ADC cell lines H23, H1573, and H2228 showed that miR-31 increases cell migration, invasion and proliferation in an ERK1/2 signalling-dependent manner. Meng et al. observed reduction in ERK1/2 signalling in miR-31 knockdown cell line, suggesting that ERK1/2 pathway activation is a main mediator of the miR-31-induced invasive phenotype. After miR-31 overexpression in $\mathrm{H} 23$ cells, the expression of several EMT-activating markers such as Vimentin, TWIST1 and SNAI1 were increased ${ }^{67}$.

Vimentin is a type III intermediate filament, a typical marker for the mesenchymal cell ${ }^{68}$. It maintains the cell shape in a quiescent cell, is involved in the highly dynamic remodelling of the cytoskeleton in motile cells ${ }^{69}$ and is upregulated during EMT in epithelial cells ${ }^{70}$, resulting in more mesenchymal phenotype and motile behaviour ${ }^{70-72}$. Gain of vimentin expression and loss of E-cadherin expression are considered to be the most important molecular markers of EMT (ref. ${ }^{73}$ ). Twist is a helix-loop-helix transcription factor which promotes EMT by down-regulating E-cadherin directly or interacting with other transcription factors ${ }^{74}$. Phosphorylation and nuclear localization of SNAI1, governed by PI3K and Wnt signalling pathways, are critical in SNAI1 regulation. SNAI1 has a key role in the regulation of EMT. SNAI1-induced EMT involves the loss of E-cadherin and claudins with accompanying 
upregulation of vimentin and fibronectin, among other biomarkers ${ }^{75}$. However, it remains unclear whether there is a connection between ERK signalling activation and EMT $\left(\right.$ ref. $\left.^{67}\right)$.

Lymphovascular invasion is positively correlated with the increased expression of miR-183 in lung adenocarcinoma tissues compared to lung adenocarcinoma without lymphovascular invasion. Together with miR-183, miR210 was also shown to be upregulated and miR-34 was down-regulated in LAD compared to normal control lung tissue by microarray method. Pak et al. also showed that miR-183 expression was significantly higher in adenocarcinoma with EGFR exon 19 mutations than those without mutation. Pak et al. assume that miR-183 could play an oncogenic role in conjunction with EGFR amplification, PTEN loss, and AKT activation ${ }^{76}$. miR-183 knockdown of tumour cell lines caused deregulation of a miRNA network composed of miR-183-EGR1-PTEN in synovial sarcoma, RMS, and colon cancer cell lines and the zinc finger transcription factor early growth response-1 (EGR-1) (ref. ${ }^{77}$ ), known as a gene essential for growth, proliferation, or differentiation, is a direct regulator of PTEN (ref. ${ }^{78}$ ). MiR-183 has a potential oncogenic role through the regulation of 2 tumour suppressor genes, EGR1 and PTEN and the deregulation of this fundamental miRNA regulatory network may be central to many tumour types ${ }^{77}$.

MiR-181b expression in 126 pairs of surgically removed NSCLC tissues and their corresponding normal lung tissues was measured by real-time quantitative RTPCR. The results showed that miR-181b expression was significantly down-regulated in NSCLC tissues compared to their normal counterparts. The low miR-181b expression was found to be closely correlated with larger tumour size, higher p-TNM stage and positive lymph node metastasis of NSCLC patients ${ }^{79}$. Neuropilin-1 (NPR-1) was identified as a target of miR-181b and down-regulated by miR-181b. NPR-1 is a mediator of lung branching and angiogenesis in embryonic development and angiogenesis in cancer ${ }^{80-83}$. NPR-1 overexpression was found in NSCLC tissues compared to normal adjacent tissues and this demonstrated that NPR-1 might be closely correlated with invasion and metastasis of NSCLC ( ref. $^{84}$ ).

Sun et al. compared normal lung tissues, NSCLClymph node positive and -lymph node negative. The results demonstrated that the relative levels of miR-124 were decreased in NSCLC- lymph node positive tissues. MiR-124 was also suppressed in highly aggressive cell lines H522 and H1975. MYO10 was subsequently identified as a novel functional downstream target of miR-124, and was up-regulated in node-positive NSCLC tissues. Knockdown of MYO10 inhibited cell migration, whereas forced MYO10 expression markedly rescued miR-124-mediated suppression of cell metastasis. Further experiments showed that miR-124 is down-regulated by NF-kB (ref. ${ }^{85}$ ). Myo10 is a motor protein best known for its role in filopodia formation ${ }^{86}$. To escape the primary tumour, cancer cells also build structures called invadopodia, actin-rich protrusions with proteolytic activity are capable of digest- ing surrounding extracellular matrix. Myo10 is the key component of invadopodia ${ }^{87}$.

Sun et al. continued with the research and found increased levels of IL- 6 and IL- 8 through NF- $\mathrm{kB}$, in highly invasive cells. They demonstrated that the IL-6-mediated activation of the NF- $\kappa$ B pathway could suppress the expression of miR-124, promoting MYO10 expression and subsequent cell aggressiveness ${ }^{85}$. It was also demonstrated that that IL-6-mediated STAT3 activation could suppress the expression of miR-124 by downregulation of $\mathrm{HNF} 4 \alpha$, which could increase miR-124 levels by binding to the promoter $^{88}$. Another study, Xie et al. revealed that miR-124 is under-expressed in NSCLC samples compared to adjacent normal tissues. Their experiments also indicated that miR124 directly targeted and decreased SOX8 in NSCLC cell lines. Moreover, increased SOX8 expression was detected in tumour samples which correlated to lymph node metas$\operatorname{tasis}^{89}$. There are few reports on SOX8 in cancer. Zhang et al. reported that SOX8 promoted cancer cell proliferation in vitro and that its expression correlated with elevated $\beta$-catenin levels in hepatocellular carcinoma ${ }^{90}$.

There is another microRNA whose biological function in NSCLC remains controversial. Zhu et al. showed that miR-224 expression levels were significantly down-regulated in NSCLC compared to corresponding noncancerous lung tissues and in human NSCLC cell lines A549, H460, 95D, and H358 compared to normal human bronchial epithelial cell line $16 \mathrm{HBE}$. In addition, decreased miR224 expression was significantly lower in samples with lymph node metastasis and advanced TNM stage. Low miR-224 levels were found in $60 \%$ of patients with lymph node metastasis, and in $28.6 \%$ of patient samples without lymph node metastasis. Furthermore, transfection of miR224 mimics in NSCLC A549 cells was able to reduce cell proliferation, invasion, and migration, and promote cell apoptosis $^{91}$. On the other hand, Cui et al. compared primary lung adenocarcinomas with lymph node metastasis and primary lung adenocarcinomas without lymph node metastasis. Of 12 up-regulated miRs, only mir-31 positively associated with lymph node metastasis and negatively correlated with survival in patients with LAD. Further analysis using NSCLC cases (LAD+SCC) and normal adjacent tissues showed that miR-224 was significantly up-regulated in both LAD and SCC compared to normal tissues. In addition, Cui et al. compared ADC patients with available staging and miRNA expression data, patients with and patients without LNM, and found that miR-224 was markedly up-regulated in patients with LNM compared to those without LNM. They further evaluated miR-244 expression in metastasized lung cancer tissues and primary lung cancer tissues and found stronger miR-224 expression in metastasized lung cancers compared with primary lung cancers. Further analysis showed that miR-224 expression promotes cell migration, invasion, and proliferation by directly targeting and significantly decreasing tumour suppressors $\mathrm{TNF} \alpha$-induced protein 1 (TNFAIP1) and SMAD4 in both LAD and SCC. Moreover, they found promoter hypermethylation and activated ERK signalling to be involved in the regulation of miR-224 expression in 
NSCLC. Up-regulated miR-224 facilitates tumour progression by shifting the equilibrium of the partially antagonist functions of TNFAIP1 and SMAD4 to enhanced invasion and growth in NSCLC (ref. ${ }^{92}$ ). It has been reported that TNFAIP1 stimulates DNA polymerase delta activity in vitro, suggesting that TNFAIP1 might be involved in DNA synthesis and apoptosis ${ }^{92,93}$. SMAD4 mediates TGF-beta signal transduction ${ }^{94}$. Aberrant TGF-beta signal transduction is a common feature of lung cancers. Inactivation of SMAD4 is thought to play a role in the inactivation of TGF-beta signalling ${ }^{95}$. Cui et al. reported that caspase 3 (CASP3) and caspase7 (CASP7) are targets of miR-224 in NSCLC, and that miR-224 promotes lung cancer cell proliferation and migration in part by directly targeting CASP7 and downregulating its expression. In addition, miR-224 attenuated TNF- $\alpha$ induced apoptosis by direct targeting of CASP3 resulting in reduction of cleaved PARP1 expression in lung cancer cells ${ }^{96}$. Both CASP 3 and CASP7 are effector caspases that perform the downstream execution steps of apoptosis by cleaving important cellular substrates ${ }^{97}$. CASP7 is highly related to CASP3. These two caspases are activated in both death receptor- and mitochondria- induced apoptosis ${ }^{98,99}$.

Ge et al. used the RT-PCT method to assess the expression levels of miR-148b. The results showed that the expression of miR-148b was decreased in NSCLC tissues compared to corresponding adjacent normal lung tissues. A low miR-148b expression was measured in $77.5 \%$ of NSCLC samples LNM+ and in only $38.2 \%$ of NSCLC samples LNM-, suggesting that miR-184b might be associated with lymph node metastasis ${ }^{100}$. Serum mir-148b together with miR-148a, miR-152 and miR-21 were dysregulated in NSCLC patients compared to healthy controls. The first three microRNAs may associate with advanced stage, large tumour size, malignant cell differentiation, and lymph node metastasis. The microRNA levels were as follows: low mir-148b expression was observed in $55.1 \%$ of NSCLC LNM+ patients and in 44\% of NSCLC LNM- patients; low miR-148a levels were found in $57.5 \%$ of NSCLC LNM+ patients and in 32\% of NSCLC LNMpatients; the miR.152 was down-regulated in $54.3 \%$ of NSCLC LNM+ and in 48\% of NSCLC LNM- patients. High expression of miR-21 correlated only with large size tumour and advanced cancer stage ${ }^{101}$.

Functional assays demonstrated that miR-148a decreased Rho-associated protein kinase 1 (ROCK1) protein expression in NSCLC cells and inhibited EMT (ref. ${ }^{102}$ ). MiR-148b functions as a suppressor of cell proliferation and migration in NSCLC. The suppresion is caused by the means of direct targeting a pro-oncogene, a carcinoembryonic antigen (CEA) (ref. ${ }^{103}$ ), widely upregulated in NSCLC specimens. This pro-oncogene is involved in cell-cell recognition and modulates cellular processes that range from the shaping of tissue architecture to neovascularization ${ }^{104}$. Su et al. described the ADAM metallopeptidase domain 17 (ADAM17) as a direct target of miR-152, down-regulated in NSCLC. ADAM17 inversely correlates with miR-152 in NSCLC tissues. ADAM17 silencing by miR-152, induced suppression of cell proliferation, colony formation, migration and invasion ${ }^{105}$. Another direct tar- get of miR-152 was fibroblast growth factor 2 (FGF2). FGF2 knockdown suppressed cell proliferation, colony formation, migration and invasion in the A549 NSCLC cell line. FGF2 also plays essential roles in tumour angiogenesis $^{106}$.

Wan et al. showed significant downregulation of miR409-3p in primary lung adenocarcinoma, compared to corresponding noncancerous tissues, and this correlated with aggressive phenotype, poor prognosis and higher incidence of LNM. $60.5 \%$ of NSCLC LNM+ patients had low miR-409-3p expression and only $39.5 \%$ of NSCLC LNM- patients had low miR-409-3p expression. Further investigations indicated that miR-409-3p directly targeted the hepatocyte growth factor receptor (c-Met). C-Met inversely correlated with miR-409-3p expression in human lung adenocarcinoma tissues ${ }^{107}$. C-Met is a receptor tyrosine kinase that after binding with hepatocyte growth factor, activates the Akt signalling pathway among others ${ }^{108}$. C-Met plays critical roles in growth, motility, migration and invasion ${ }^{109,110}$ and has been found to be aberrantly activated in various human cancers via mutation, amplification and/or protein expression ${ }^{111}$.

$\mathrm{Yu}$ et al. observed down-regulation of miR-193-3p and miR-193-5p in NSCLC; and in highly metastatic cells A549, H1299 and SPC-A-1sci compared to NSCLC weakly metastatic cells LC-21, SPC-A-1 and H358 in vitro. Decreased levels of these miRNAs significantly associated with tumour node metastasis and lymph node metastasis. Median expression levels of miR-193-3p in NSCLC samples with metastasis were $0.768 \pm 0.714$ and in NSCLC samples without metastasis $1.340 \pm 0.978$. A similar situation was observed in measurement of miR-193-5p where the median expression $1.769 \pm 1.443$ was lower in NSCLC samples with metastasis and higher expression $2.882 \pm 2.822$ was found in NSCLC samples without metastasis. ERBB4 and S6K2 were identified as direct targets of miR-193-3p and PIK3R3 and mTOR were the direct targets of miR-193-5p. All four targets are potential metastasis promoters. MiR-193a-3p/5p might function as a tumour suppressor and inactivate PIK3R3 /Akt/mTOR signalling pathway and ERBB signalling pathway ${ }^{112}$. The ErbB signalling network instructs the execution of key cellular processes, such as cell survival, proliferation and motility, through the signals of defined strength and duration. In contrast, unabated ErbB signalling disrupts tissue homeostasis that leads to cell transformation ${ }^{113}$. The PI3K/Akt/mTOR signalling pathways are crucial to many physiological and pathological conditions, such as cell proliferation, survival, differentiation, adhesion, motility and invasion ${ }^{114}$. Dysregulation of the PI3K/AKT/ mTOR pathway is involved in lung tumourigenesis and it has been associated with high grade tumours (G3-G4) and advanced disease (stage III) (ref. ${ }^{115}$ ). Accordingly, inhibitors of PI3K signalling have been suggested as potential therapeutic agents in NSCLC. Deregulation of this pathway occurs through a variety of mechanisms including activation of tyrosine kinase receptors upstream of PI3K, PIK3CA amplification as well as mutations in KRAS, PI3K or AKT, or loss of negative regulation by the tumour suppressor gene PTEN (ref. ${ }^{114}$ ). 
He et al. showed that the expression levels of miR675-5p in NSCLC tissues were significantly reduced compared to those in adjacent non-cancerous tissues. $89 \%$ of NSCLC metastasis positive patients and $61 \%$ of NSCLC metastasis negative patients had low expression levels of miR-675-5p suggesting that there is a negative correlation with lymph node metastasis. Further assay showed that G protein-coupled receptor 55 (GPR55) was a direct target gene of miR-675-5p. GPR55 up regulation contributes to aggressive behaviour in various cancer types. Overexpression of miR-675-5p can lead to the down regulation of GPR55 and its signalling pathway. The study of $\mathrm{He}$ et al. also examined the expression of GPR55 signalling downstream target genes and found that the expression of p-ERK, cyclin D1, MMP9 and MMP2 were decreased in NSCLC A549 and HTB-182 cells that stably over-expressed miR-675-5p (ref. ${ }^{116}$ ). P-ERK is an important component in cell survival. When p-ERK was inhibited, cell viability decreased and the expression of p-c-Jun and cyclin D1 was reduced ${ }^{117}$. Cyclins act together with their CDK partners to drive cells from one phase of the cell cycle to the next ${ }^{118}$. Expression of cyclin D1 is induced by numerous mitogens. For example, stimulation of the PI3K/Akt pathway leads to activation of NF-kB, a transcription factor that induces production of cyclin D1 (ref. ${ }^{119}$ ). Current data indicate that cyclin D1 overexpression is a pivotal element in the process of malignant transformation in the lung and other tissues ${ }^{118}$. Matrix metalloproteinases are the key mediators of the extracellular matrix that regulates multiple cellular functions required for tumour invasion ${ }^{120-123}$. MMP9 is an important matrix proteinase that degrades collagen type IV, the major component of the basement membrane. Overexpression of MMP9 often facilitates cancer metastasis. MMP-2 has also been reported to maintain extracellular matrix rigidity and promote motility and proliferation ${ }^{124,125}$.

Interesting results were also presented by Wang et al. who measured the expression levels of miR-29b. Quantitative RT-PCR analysis of fresh normal lung tissue versus lung tumour tissue showed that the relative expression of miR-29b in normal tissues was -0.463 . The expression level of miR-29b in NSCLC patients with lymphatic metastasis was $-2.389 \pm 1.302$ and in NSCLC patients without lymphatic metastasis was higher: $-1.505 \pm 0.799$. Moreover, in vitro studies revealed that miR-29b suppresses cell proliferation, migration and invasion in A549 cells indicating that upregulation of this microRNA might be involved in the metastasis of NSCLC. MiR-29b targeted matrix metalloproteinase 2 (MMP2) and phosphatase and tensin homolog (PTEN). Following experiments showed that miR-29b regulated MMP2 negatively but there were no obvious changes in PTEN mRNA or protein expression levels in miR-29b transfected or miR-29b inhibitor transfected cells ${ }^{126}$. PTEN regulates tumour cell growth, cell cycle, apoptosis and metastasis by regulating multiple signalling pathways negatively ${ }^{127,128}$.

Tang et al. aimed to identify the relationship between miR-203 expression and its clinicopathological significance in NSCLC patients. The relative level of miR-203 was 6.12 \pm 6.25 in NSCLC tissues, remarkably more down- regulated than that of paired normal tissues: $7.88 \pm 5.56$. Mir-203 expression negatively correlated with lymphatic metastasis. The relative level was $7.89 \pm 5.67$ in NSCLC patients without lymphatic metastasis and $4.69 \pm 6.37$ in NSCLC lymphatic metastasis. In vitro experiments confirmed the suppressive role of miR-203 mimic on the cell growth of H460, A549, H1299, PC9 and H292 NSCLC cells $^{129}$. Other authors have described miR-203 target genes in NSCLC. Wang et al. demonstrated that miR-203 played a role in proliferation, apoptosis and migration by targeting PKC $\alpha$ (ref. ${ }^{130}$ ). PKC $\alpha$ has been shown to bind and phosphorylate the scaffold protein discs large homo$\log 1$ (DLG1) and promote cell migration in NSCLC cells $^{131}$. Jin et al. identified survivin as a direct gene inhibited by miR-203 (ref. ${ }^{132}$ ). Survivin is a suppressor of apoptosis in the inhibitor of apoptosis protein gene family ${ }^{133}$. Saini et al. suggest that survivin regulated by miR-203 promotes metastasis of prostate cancer ${ }^{134}$. Wang et al. reported that miR-203 might restrain cell proliferation and migration and promote cell apoptosis of lung cancer cells by targeting SRC, a non-receptor tyrosine kinase which plays an essential role in cancer development since it can promote survival, angiogenesis, proliferation and invasion pathways ${ }^{135}$.

According to Ren et al., miR-92a belongs to the group of microRNAs that are significantly upregulated in NSCLC compared to adjacent normal tissues. Its expression is connected with lymph node metastasis. $3.33 \pm 0.42$ was the miR-92a expression in NSCLC lymph node positive patients. In contrast, $2.11 \pm 0.29$ only was the expression level of miR-92a in NSCLC lymph node negative patients. Upregulation of miR-92a by miR-92a mimic in A549 cells significantly enhanced migration and invasion, while downregulation of miR-92a by antimiR-92 in A549 cells significantly inhibited migration and invasion as expected. TargetScan6.2 and miRanda, western blotting and qRT-PCR showed that PTEN, a tumour suppressor gene, is a direct target of and down-regulated by miR-92a (ref. ${ }^{136}$ ). It is established that PTEN functions as a negative regulator of the PI3K/Akt pathway via dephosphorylation of PI $(3,4,5) \mathrm{P} 3$ (ref. $\left.{ }^{137}\right)$.

Chen et al. evaluated the expression of miR-30b in NSCLC (ref. ${ }^{138}$ ). The median \pm SD expression levels of miR-30b were associated with lymph node metastasis as follows: NSCLC patients LNM+ had 0.2147 \pm 0.0670 levels; NSCLC patients LNM- had 0.3129 \pm 0.1234 levels. Lower levels of miR-30b were in NSCLC compared to adjacent normal tissue. Furthermore, these authors evaluated the expression of collagen triple helix repeat containing 1 (Cthrc1). The median \pm SD expression levels of Cthrc1 inversely correlated with miR-30b expression: NSCLC patients LNM+ had $2.4555 \pm 0.3352$ expression levels and NSCLC patients LNM- had $2.1952 \pm 0.3290$ levels. In vitro examinations revealed that miR-30b inhibits cell invasion and migration through targeting and downregulating Cthrc1 of A549 and Calu-3 cells. Not only was the expression of Cthrc1 decreased, MMP-2 and MMP-9 expression was also reduced while TIMP-1 expression was increased in miR-30b mimic transfected A549 and Calu-3 cells ${ }^{138}$. TIMP1 regulates extracellular 
matrix catabolism but the major effect in tumour tissue is promotion of cell growth and anti-apoptotic activity ${ }^{139}$.

Ectopic up-regulation of Cthrc1 in cancer cells might result in elevated invasive and proliferative abilities. The biological effect of Cthrc1 on metastasis and proliferation is mediated by the activation of the Wnt/ $\beta$-catenin pathway $^{140}$.

Interesting research was reported by Yan et al. who evaluated expression of miR-761 not only in NSCLC patients' tissues and cell lines but also in NSCLC patients' serum. MiR-761 was significantly upregulated in both NSCLC serum and tissues compared to normal participants and paired noncancerous tissues. High expression levels of miR-30b were measured in $66.6 \%$ of NSCLC LNM+ patients while there were no NSCLC LNMpatients with high expression levels of miR-761 at all. Ectopic expression of miR-761 promoted cell proliferation and metastasis in human lung cancer H460 cells, while miR-761 inhibitor reduced proliferation rates and metastasis in human lung cancer H23 cell line. Furthermore, luciferase reporter assay and functional analyses indicated that miR-761 directly targeted ING4 and TIMP2. Expression of miR-761 is negatively correlated with ING4 and TIMP2 in NSCLC (ref. ${ }^{141}$ ). TIMP2 promotes upregulation of E-cadherin/ beta-catenin complex, inhibits MMP-2 blood vessel formation, inactivating receptor tyrosine kinases including VEGFR-2 and FGFR-2 through de-phosphorylation mediated by SHP-1 of A549 cells $^{142}$. ING4 was found to down-regulate interleukin IL6, IL-8, MMP-2 and MMP-9 expression in the human lung adenocarcinoma cell line A549 (ref. ${ }^{143}$ ). ING4 has been shown to interact physically with the p65 subunit of nuclear factor (NF)- $\mathrm{kB}$ and regulate angiogenesis through transcriptional repression of NF- $\mathrm{kB}$-responsive genes in brain tumours ${ }^{144}$.

Noticeable down-regulated expression of miR-375 was detected in $89 \%$ of NSCLC samples compared to matched healthy tissue. The means \pm SD $\Delta C T$ value of miR-375 in NSCLC tissue was $12.13 \pm 1.62$ compared with $8.47 \pm$ 0.86 in adjacent healthy tissue. Decreased level of miR375 was significantly correlated with advanced disease stage and lymphatic metastasis. The mean \pm SD $\Delta$ CT value of miR-375 in NSCLC tissues with positive lymphatic metastasis was $14.39 \pm 1.52$ and in NSCLC tissues with negative lymphatic metastasis was $10.22 \pm 1.05$ (ref. ${ }^{145}$ ). Moreover, the plasma level of miR-375 was examined. The levels of plasma miR-375 were significantly lower in $61.5 \%$ of NSCLC patients with metastasis than those in $42.4 \%$ of patients without metastases ${ }^{146}$. The downregulation of miR-375 is mainly caused by aberrant promoter hypermethylation ${ }^{147}$. MiR-375 could bind directly to the 3'-untranslated region of AEG-1, an important oncogene involved in multiple aspects of cancer development and progression $^{148}$. AEG-1 induces epithelial-mesenchymal transition in lung cancer through activating $\mathrm{Wnt} / \beta$-catenin signalling ${ }^{149}$

Lan et al. described the validated clinical significance of miR-133a expression and clinicopathological significance in NSCLC. The evaluated mean $\pm \mathrm{SD}^{2-\Delta \mathrm{cq}}$ miR-133a expression by qRT-PCR in NSCLC tissues was 2.0108 \pm 1.3334 , significantly lower than that of the adjacent non-cancerous tissue $3.6430 \pm 2.2625$. MiR-133a expression was $1.8035 \pm 1.3079$ in NSCLC patients with lymph node metastasis than in those without $2.0787 \pm 1.3777$. The expression was also negatively correlated to tumour size, TNM stages and EGFR protein expression ${ }^{150}$. An example of the one microRNA targeting more genes provides the experiments revealing the biological functions of miR-33a. This microRNA, down-regulated in malignant lung cancer cells, directly suppresses multiple oncogenic membrane receptors including IGF-1R, TGFBR1 and EGFR thus inhibits cell invasive capacity in NSCLC (ref. ${ }^{151}$ ). Wang et al. found that the expression levels of miR-133a were higher in NSCLC cells with low invasiveness (EKVX and H23) than in those with high invasive ability (A549, H441 and H1299) suggesting that miR-133a is dysregulated in lung cancer and that the expression of miR-133a negatively correlates with cell invasiveness. The expressions of EGFR and IGF-1R were decreased by the ectopic expression of miR-133a in CL1-5 and A549 cells. Downregulation of TGFBR1 expression was observed in A549 cells but not in CL1-5 cells. MiR-133a regulates AKT activity through suppressing its downstream targets of IGF-1R and TGFBR1. MiR-133a regulates IGF-1-and TGF-b-mediated downstream signalling through downregulating their receptors. In vivo studies showed that miR-133a suppresses cancer metastasis in mice model ${ }^{134}$. IGF-1R signalling pathway has important roles in tumourigenesis, metastasis, and resistance to existing forms of anti-cancer therapy. Targeting the IGF signalling pathway might be one evolving anticancer therapy with potential efficacy ${ }^{152}$. TGFBR1pathway is critical for cell growth and differentiation. In the pathway, TGF- $B$ binds directly to TGFBR2, and is then recognized by TGFBR1, which is phosphorylated and activated by TGFBR2 (ref. ${ }^{153}$ ) TGF- 3 signalling alterations have been identified in development and progression of several epithelial-type human malignancies, including NSCLC (ref. ${ }^{154-156}$ ). Constitutively decreased type I TGF-beta receptor (TGFBR1) expression is emerging as a novel tumour-predisposing phenotype ${ }^{157}$. EGFR signalling plays a role in cell growth, differentiation, survival and proliferation ${ }^{158}$. The strength and duration of the signal are strictly controlled and dysregulation of this signalling pathway can lead to carcinogenesis ${ }^{159,160}$.

\section{MiRNA involved in bone metastasis}

Guo et al. showed that the expression of miR-21 in NSCLC patients with bone metastasis was significantly higher than that in patients with bone tuberculosis. This study demonstrated that miRNA-21 promoted H2170 NSCLC cell proliferation by inhibiting cell apoptosis via the increase of COX-19 expression ${ }^{161}$. COX-19 is a protein that affects COX subunit assembly, which subsequently influences COX activity ${ }^{162}$. Alteration of COX activity induces cell apoptosis ${ }^{163}$.

The microRNAs involved in NSCLC metastasis formation are summarized in Fig 1. 


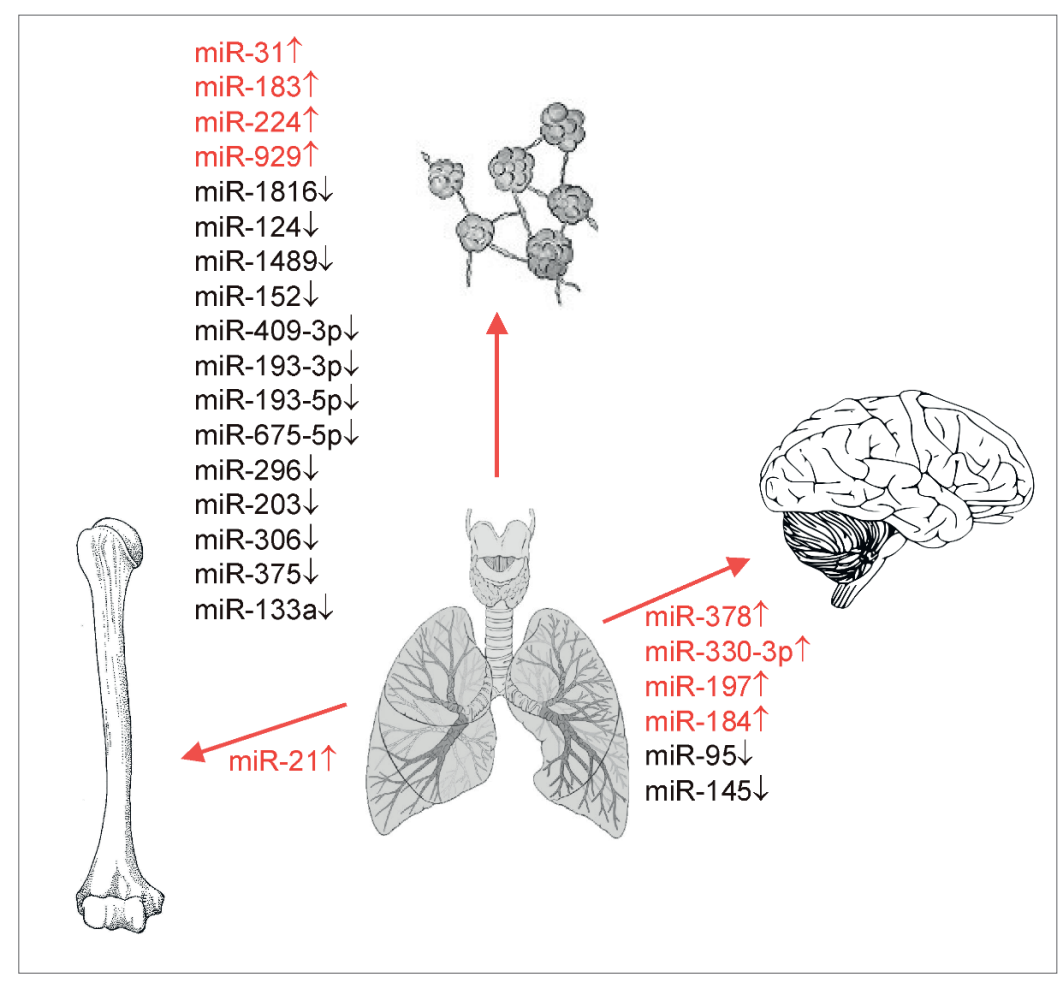

Fig. 1. Altered microRNA expression in NSCLC leading to metastasis spread to brain, lymph nodes and bones.

\section{Current in vitro studies selecting potential miRNAs involved in the process of migration and metastasis of NSCLC cell lines.}

Based on the information that the expressions of miR$193 \mathrm{~b}$ in cancer tissues are significantly lower than those in normal lung tissues, $\mathrm{Hu}$ et al. further investigated the effects of miR-193b on A549 cell proliferation, migration, invasion and potential target genes. The results showed that miR-193b inhibits cell proliferation and triggers G1 phase arrest, suppresses the migration and invasion and represses the expression of CCND1 and urokinase-type plasminogen activator (uPA) directly in A549 cells with miR-193b transfection. The data showed that the expression levels of CCND1 and UPA in NSCLC tissues were higher than those in adjacent normal tissues ${ }^{164}$. Two key classes of regulatory molecules, cyclins and cyclin-dependent kinases (CDKs), determine a cell's progress through the cell cycle ${ }^{165}$. CCND1 forms a complex with and functions as a regulatory subunit of CDK4 or CDK6, and therefore controls cell cycle G1/S transition. Mutations and overexpression of this gene altering the cell cycle progression, are observed in a variety of tumours and may contribute to tumourigenesis ${ }^{166,167}$. The uPA is a serine protease which catalyzes the conversion of the inactive zymogen plasminogen into the active broad-spectrum plasmin. Plasmin degrades matrix proteins and activates other proteases, including matrix metalloproteinases ${ }^{168}$. Through degrading the extracellular matrix proteins, uPAs regulate cancer progression processes including cancer cell motility, extracellular matrix invasion, and metastasis ${ }^{169}$.

Savita and Karunagaran generated a stable clone of miR-106b-25 cluster and the empty vector in NSCLC
H1299 cells. Expression of $\beta$-TRCP2 mRNA was significantly lower in H1299 with miR-106b-25 cluster than in empty vector cells. SNAI1 protein expression was higher in H1299 with miR-106b-25 cluster than in empty vector cells. MiR-106-25 cluster induced migration, invasiveness, and colony formation of $\mathrm{H} 1299$ cells. These data indicate that MiR-106-25 cluster may play an important role in the metastasis of human NSCLC (ref. ${ }^{170}$ ). $\beta$-TRCP is a member of the ubiquitin ligase complex that ubiquitinates many proteins such as IjBa, WEE1, b-catenin and SNAI1 (ref. ${ }^{171}$ ).

MiR-33a, an intronic miRNA located within the sterol regulatory element-binding protein 2 (SREBP-2) gene, is expressed at low levels in the metastatic NCI-H1299 NSCLC cell line and is inversely correlated with the expression of its target gene, Twist1. Twist1 knockdown blocks EMT-related metastasis and forced expression of miR-33a inhibits lung cancer metastasis in a xenograft animal model suggesting that miR-33a targets Twist 1 and inhibits invasion and metastasis in NSCLC clinically. MiR-33a is found to be at low levels in NSCLC patients and down-regulation of miR-33a predicts poor prognosis $^{172}$. Twist 1 promotes EMT in part, by directly repressing E-cadherin expression by recruiting the nucleosome remodelling and deacetylase complex for gene repression and by upregulating Bmi1, AKT2, YB-1, etc. (ref. ${ }^{173}$ ).

The metastasis-associated gene 1 (MTA1) is one of the metastasis-related genes which is over-expressed in numerous carcinomas including NSCLC (ref. ${ }^{174}$ ). For this reason, Zhang et al have tried to identify microRNAs that suppress malignancy in HEK293T, SPC-A-1 and 95D NSCLC cells by targeting MAT1. Among candidate mi- 
Table 1. Contribution of dysregulated microRNAs and their downstream target genes to metastatic processes of NSCLC tissues and cells.

\begin{tabular}{|c|c|c|}
\hline MicroRNA & Affected gene & Biological function of the gene \\
\hline \multirow[t]{2}{*}{ miR-95-3p $\downarrow$} & cyclin D1 $\uparrow$ & cell cycle progression \\
\hline & ABLIM2 $\downarrow$ & cytoskeletal organization \\
\hline \multirow[t]{3}{*}{$\operatorname{miR}-378 \uparrow$} & VEGF $\uparrow$ & angiogenesis \\
\hline & MMP-2 $\uparrow$ & angiogenesis \\
\hline & MMP-9 $\uparrow$ & angiogenesis \\
\hline $\operatorname{miR}-330-3 p \uparrow$ & EGR2 $\downarrow$ & proliferation \\
\hline $\operatorname{miR}-197 \uparrow$ & FUS1 $\downarrow$ & apoptosis inducer \\
\hline $\operatorname{miR}-184 \uparrow$ & SOX7 $\downarrow$ & tumorigenesis \\
\hline \multirow[t]{3}{*}{$\operatorname{miR}-145 \downarrow$} & fascin $1 \uparrow$ & invasion \\
\hline & NUDT1 $\uparrow$ & oxidative stress \\
\hline & $\mathrm{EGFR} \uparrow$ & growth \\
\hline \multirow[t]{3}{*}{$\operatorname{miR}-328 \uparrow$} & PRKCA $\uparrow$ & adhesion \\
\hline & VEGFD $\uparrow$ & adhesion \\
\hline & NOTCH1 $\uparrow$ & adhesion \\
\hline \multirow[t]{3}{*}{$\operatorname{miR}-31 \uparrow$} & vimentin $\uparrow$ & EMT \\
\hline & TWIST1 $\uparrow$ & EMT \\
\hline & SNAI $1 \uparrow$ & EMT \\
\hline \multirow[t]{3}{*}{$\operatorname{miR}-183 \uparrow$} & EGFR $\uparrow$ & growth and proliferation \\
\hline & PTEN $\downarrow$ & growth and proliferation \\
\hline & $\mathrm{AKT} \uparrow$ & growth and proliferation \\
\hline miR-181b $\downarrow$ & NPR-1 $\uparrow$ & angiogenesis \\
\hline \multirow[t]{2}{*}{ miR-124 $\downarrow$} & MYO10 $\uparrow$ & migration \\
\hline & SOX8 $\uparrow$ & proliferation \\
\hline \multirow[t]{3}{*}{$\operatorname{miR}-224 \uparrow$} & TNFAIP1 $\downarrow$ & invasion proliferation and migration \\
\hline & SMAD4 $\downarrow$ & invasion, proliferation and migration \\
\hline & CASP7 $\downarrow$ & invasion, proliferation and migration \\
\hline miR-148b $\downarrow$ & $\mathrm{CEA} \uparrow$ & proliferation and migration \\
\hline miR-148a $\downarrow$ & ROCK1 $\uparrow$ & EMT \\
\hline \multirow[t]{2}{*}{$\operatorname{miR}-152 \downarrow$} & ADAM17 $\uparrow$ & invasion, proliferation and migration \\
\hline & FGF2 $\uparrow$ & invasion, proliferation and migration \\
\hline miR-409-3p $\downarrow$ & c-Met $\uparrow$ & growth, motility, invasion, migration \\
\hline \multirow[t]{2}{*}{ miR-193-3p $\downarrow$} & ERBB $4 \uparrow$ & survival, motilty, proliferation \\
\hline & S6K2 $\uparrow$ & survival, motilty, proliferation \\
\hline \multirow[t]{2}{*}{ miR-193-5p $\downarrow$} & PIK3R3 $\uparrow$ & survival, motilty, proliferation \\
\hline & $\operatorname{mTOR} \uparrow$ & survival, motilty, proliferation \\
\hline miR-675-5p $\downarrow$ & GPR55 $\uparrow$ & cell survival \\
\hline $\operatorname{miR}-29 \mathrm{~b} \downarrow$ & $\mathrm{MMP} 2 \uparrow$ & angiogenesis \\
\hline miR-203 $\downarrow$ & $\begin{array}{l}\text { PKC } \alpha \uparrow \\
\text { survivin } \uparrow\end{array}$ & $\begin{array}{l}\text { proliferation, apoptosis, migration } \\
\text { apoptosis }\end{array}$ \\
\hline $\operatorname{miR}-92 \mathrm{a} \uparrow$ & PTEN $\downarrow$ & growth and proliferation \\
\hline \multirow[t]{4}{*}{ miR-30b $\downarrow$} & CTHRC1 $\uparrow$ & invasiveness and proliferation \\
\hline & MMP- $2 \uparrow$ & angiogenesis \\
\hline & MMP-9 $\uparrow$ & angiogenesis \\
\hline & TIMP-1 $\downarrow$ & growth and antiapoptosis \\
\hline $\operatorname{miR}-375 \downarrow$ & AEG-1 $\uparrow$ & cancer development and progression \\
\hline $\operatorname{miR}-21 \uparrow$ & COX-19 $\uparrow$ & proliferation and apoptosis \\
\hline \multirow[t]{2}{*}{$\operatorname{mir}-193 b \downarrow$} & CCND1 $\uparrow$ & cell cycle progression \\
\hline & $\mathrm{uPA} \uparrow$ & cell motility, exracellular matrix invasion \\
\hline \multirow[t]{2}{*}{ miR-106b-25 $\uparrow$} & $\beta$-TRCP2 $\downarrow$ & inhibition of migration \\
\hline & SNAI1 $\uparrow$ & migration \\
\hline $\operatorname{miR}-33 \mathrm{a} \downarrow$ & Twist1 $\uparrow$ & invasion \\
\hline $\operatorname{miR}-125-3 p \downarrow$ & MAT1 $\uparrow$ & proliferation, migration and invasion \\
\hline miR-144 $\downarrow$ & AP4 $\uparrow$ & invasion \\
\hline $\operatorname{miR}-410 \uparrow$ & BRD7 $\downarrow$ & proliferation, migration and invasion \\
\hline
\end{tabular}


croRNAs, miR-125-3p was shown to post-transcriptionally regulate MTA1 in NSCLC cells and thus inhibit the proliferation, migration and invasion of NSCLC cells through MTA1 targeting and downregulation. Expression levels of miR-125-3p and MTA1 protein were examined in NSCLC tissues and matched normal tissues. There was a significant negative correlation between the expression of miR125.3p and MTA1 in NSCLC tissues ${ }^{175}$. MTA1 expression is associated with an invasive and metastatic phenotype based on microarray data ${ }^{176}$. It is a key regulator of the DNA damage response, and is involved in EMT (ref. ${ }^{177}$ ).

Recent studies have reported that activating protein-4 (AP4) is upregulated in NSCLC and predicts poor prognosis in such patients ${ }^{178-180}$. AP4 has been shown to regulate cancer metastasis in NSCLC via regulating mTor/ p21 and transforming the growth factor $\beta$ (TGF $\beta$ ) receptor signalling pathway to increase EMT to augment cell invasiveness. Bioinformatics analyses and further luciferase-reporter assay revealed that miR-144 targeted AP4 mRNA. MiR-144 overexpression inhibited AP4-mediated cell invasiveness, while miR-144 depletion increased AP4mediated cell invasiveness in the human A549 NSCLC line. The levels of miR-144 and AP4 inversely correlated in patient specimens ${ }^{180}$.

Tang et al. detected miR-25 expression in A549 cells, NSCLC and non-cancerous tissues. The expression of miR-25 in A549 cells and NSCLC tissues was significantly higher than that in normal MRC5 lung fibroblast cells and non-cancerous lung tissue. The aim of their study was to investigate the functional role of miR-25 in vitro and in vivo. Downregulation of miR-25 markedly inhibited A549 cell proliferation, induced G1 cell cycle arrest, increased cisplatin sensitivity, and suppressed the growth of tumours ina xenograft model, possibly through downregulation of its direct target cell division cycle 42 (CDC42). Mir-25 significantly down-regulated CDC42 in A549 cells ${ }^{181}$. CDC42 activation results in the stimulation of a variety of signalling cascades altering cellular processes such as cytoskeletal remodelling, establishment of cell polarity, regulation of cell migration and cell proliferation, as well as modification of transcriptional programs $^{182}$. Controversially, Zhang et al. showed that CDC42 was over-expressed in NSCLC tissues ${ }^{183}$.

MiR-410 can function as a tumour suppressor or oncogene in some malignancies. To determine its role in NSCLC, Li et al. compared the expression levels NSCLC tissues with adjacent normal tissues and four NSCLC cell lines (A549, SPC-A1, H1299 and H1650) with the normal bronchial epithelial 16HBE cell line. Expression of miR-410 was up-regulated in both human NSCLC tissues and cell lines. Overexpression of miR-410 promoted cell proliferation, migration, and invasion of A549. In addition, bromodomain-containing protein 7 (BRD7) was a direct target of miR-410. MiR-410-mediated downregulation of BRD7 led to increased Akt phosphorylation. Akt activation partially blocked miR-410-induced cell proliferation ${ }^{184}$. BRD7 is down-regulated in various malignancies ${ }^{185-187}$. However Chen and Yu found that BRD7 expression was significantly higher in NSCLC tissues compared to normal lung tissue and also in an NSCLC lymph node metastasis group than that in the non-lymph node metastasis group ${ }^{188}$. BRD7 plays critical roles in various cellular processes such as development, differentiation, growth, and metabolism ${ }^{189,190}$. BRD7might serve as a tumour suppressor by promoting p53 function and by reducing the survival signalling mediated by $\mathrm{PI} 3 \mathrm{~K} / \mathrm{Akt}$ activation $^{191}$.

The biological functions of selected microRNAs described in this review are summarized in Table1.

\section{CONCLUSION}

At this time, it is not possible to reliably predict the site of metastasis in NSCLC. Microarray technology allows us to analyze the expression levels of hundreds of RNAs in different tissues. There are differences in microRNA expression profiling between NSCLC with and without metastases. The RNA microarray profiling may thus be a useful tool to select up- or down-regulated microRNAs and consider them as unique biological characteristics and potential markers.

Based on the data from RNAmicroarrays, bioinformatics analysis is able to predict the target genes of highlighted microRNAs which provide us with complex information about cancer cell features such as enhanced proliferation, migration and invasion. Such microRNAs may then be knocked-down using siRNAs or substituted with miRNA mimics.

\section{ABBREVIATIONS}

NSCLC, non-small cell lung carcinoma; ABLIM2, actin binding LIM protein family member 2; EMT, epithelial-mesenchymal transition; MMP, matrix metalloproteinase; VEGF, vascular endothelial growth factor; BM, brain metastasis; EGR2, early grow response protein 2; FUS1, FUS RNA binding protein; SOX7, sex determining region Y; FSCN1, FUS RNA binding protein; NUDT1, nucleoside diphosphate linked moiety X-type motif 1; EGFR, epithelial growth factor receptor; IL-1, interleukin complex 1; PRKCA, protein kinase C, alpha; JAK, janus kinase; uPA, urokinase-type plasminogen activator; STAT3, signal transducer and activator of transcription 3; TWIST1, twist family bHLH transcription factor 1; SNAI1, snail family zinc finger 1; PIK3CA, phosphatidylinositol-4,5-bisphosphate 3-kinase, catalytic subunit alpha; RMS, Rhabdomyosarcoma; NPR-1, neuropilin-1; MYO10, myosin X; HNF4 $\alpha$, hepatocyte nuclear factor 4, alpha; SOX8, SRY (sex determining region Y)-box 8; TNM, tumour node metastasis; LNM, lymph node metastasis; TNFAIP1, TNF $\alpha$-induced protein 1; CASP, caspase; CEA, carcinoembryonic antigen; ADAM17, ADAM metallopeptidase domain 17; FGF2, fibroblast growth factor 2; c-Met, hepatocyte growth factor receptor; PIK3R3, phosphoinositide-3-kinase, regulatory subunit 3; KRAS, Kirsten rat sarcoma viral oncogene homolog; 
GPR55, G protein-coupled receptor 55; NF-kB, nuclear factor of kappa light polypeptide gene enhancer in B-cells; PTEN, phosphatase and tensin homolog; DLG1, discs large homolog 1; SRC, SRC proto-oncogene, non-receptor tyrosine kinase ; Cthrc1, collagen triple helix repeat containing 1; TIMP-1, TIMP metallopeptidase inhibitor 1; ING4, inhibitor of growth family, member 4; TGFBR1, type I TGF-beta receptor; TGF-13, transforming growth factor, beta 1; COX-19, COX19 cytochrome c oxidase assembly factor; CDKs, cyclin-dependent kinases; WEE1, WEE1 G2 checkpoint kinase; SREBP-2, sterol regulatory element-binding protein 2; MTA1, Metastasis-associated gene 1; AP4, activating protein-4; CDC42, cell division cycle 42; BRD7, bromodomain-containing protein 7 .

Acknowledgement: Supported by grant IGA MZ CR 14406.

Author contributions: ZP: literature search and manuscript writing; JS, JA: corrections and final approval.

Conflict of interest statement: None declared.

\section{REFERENCES}

1. Hoffman PC, Mauer AM, Vokes EE. Lung cancer. Lancet 2000;355(9202):479-85.

2. Jemal A, Siegel R, Ward E, Murray T, Xu J, Thun MJ. Cancer statistics 2007;57(1):43-66.

3. van Meerbeeck JP. Staging of non-small cell lung cancer: consensus, controversies and challenges. Lung Cancer 2001;34 Suppl 2:S95-107.

4. Grinberg-Rashi $H$, Ofek $E$, Perelman $M$, Skarda J, Yaron $P$, Hajdúch M, Jacob-Hirsch J, Amariglio N, Krupsky M, Simansky DA, Ram Z, Pfeffer R, Galernter I, Steinberg DM, Ben-Dov I, Rechavi G, Izraeli S. The expression of three genes in primary non-small cell lung cancer is associated with metastatic spread to the brain. Clin Cancer Res 2009;15(5):1755-61.

5. Ambros V. The functions of animal microRNAs. Nature 2004;431(7006):350-5.

6. Lewis BP, Burge CB, Bartel DP. Conserved seed pairing, often flanked by adenosines, indicates that thousands of human genes are $\mathrm{mi}$ croRNA targets. Cell 2005;120(1):15-20.

7. Bartel DP. MicroRNAs: genomics, biogenesis, mechanism, and function. Cell 2004;116(2):281-97.

8. Lin PY, Yu SL, Yang PC. MicroRNA in lung cancer. Br J Cancer 2010;103(8):1144-8.

9. Calin GA, Sevignani C, Dumitru CD, Hyslop T, Noch E, Yendamuri S, Shimizu M, Rattan S, Bullrich F, Negrini M, Croce CM. Human microRNA genes are frequently located at fragile sites and genomic regions involved in cancers. Proc Natl Acad Sci U S A 2004;101(9):299930048.

10. Barger JF, Nana-Sinkam SP. MicroRNA as tools and therapeutics in lung cancer. Respir Med 2015;109(7):803-12.

11. Hashimoto Y, Akiyama Y, Yuasa Y. Multiple-to-multiple relationships between microRNAs and target genes in gastric cancer. PLoS One 2013;8(5):e62589.

12. Brodersen $P$, Voinnet $O$. Revisiting the principles of microRNA target recognition and mode of action. Nature Rev Mol Cell Biol 2009;10(2):141-8.

13. Meng F, Henson R, Wehbe-Janek H, Ghoshal K, Jacob ST, Patel T. MicroRNA-21 regulates expression of the PTEN tumour suppressor gene in human hepatocellular cancer. Gastroenterol 2007;133(2):647-581.

14. Yanaihara N, Caplen N, Bowman E, Seike M, Kumamoto K, Yi M, Stephens RM, Okamoto A, Yokota J, Tanaka T, Calin GA, Liu CG, Croce CM, Harris CC. Unique microRNA molecular profiles in lung cancer diagnosis and prognosis. Cancer Cell 2006;9(3):189-98.

15. Naidu S, Magee P, Garofalo M. MiRNA-based therapeutic intervention of cancer. J Hematol Oncol 2015;8:68.
16. Hwang $S J$, Lee HW, Kim HR, Song $H J$, Lee $D H$, Lee $H$, Shin $C H$, Joung JG, Kim DH, Joo KM, Kim HH,. Overexpression of microRNA-95-3p suppresses brain metastasis of lung adenocarcinoma through downregulation of cyclin D1. Oncotarget 2015;6(24):20434-48.

17. Gautschi O, Ratschiller D, Gugger M, Betticher DC, Heighway J. Cyclin D1 in non-small cell lung cancer: a key driver of malignant transformation. Lung Cancer 2007;55(1):1-147.

18. Arber N, Hibshoosh H, Moss SF, Sutter T, Zhang Y, Begg M, Wang $S$, Weinstein IB, Holt PR. Increaed experwssion of cyclin D1 is an early event in multistage colorectal carcinogenesis. Gastroenterol 1996;110(3):669-74.

19. Ohnishi Y, Watanabe M, Wato M, Tanaka A, Kakudo K, Nozaki M Cyclin D1 expression is correlated with cell differentiation and cell proliferation in oral squamous cell carcinomas. Oncol Lett 2014 Feb 13 [Epub ahead of print] doi: 10.3892/ol.2014.1880.

20. Oyama T, Kashiwabara K, Yoshimoto K, Arnold A, Koerner F. Frequent overexpression of the czclin D1 oncegene in invasive lobular carcinoma. Cancer Res 1998;58(13):2876-80.

21. Arato-Ohshima T, Sawa H. Over-expression of cyclin D1 induces glioma invasion by increasing matrix metalloproteinase activity and cell motility. Int J Cancer 1999;83(3):387-92.

22. Du B, Wang Z, Zhang X, Feng S, Wang G, He J, Zhang B. MicroRNA-545 suppresses cell proliferation by targeting cyclin D1 and CDK4 in lung cancer cells. PLoS One 2014;9(2):e88022.

23. Besson A, Dowdy SF, Roberts JM. CDK inhibitors: cell cycle regulators and beyond. Dev Cell 2008;14(2):159-69.

24. Neumeister P, Pixley FJ, Xiong $Y$, Xie H, Wu K, Ashton A, Cammer M, Chan A, Symons M, Stanley ER, Pestell RG. Mol Biol Cell Feb 21 [Epub ahead of print] doi:10.1091/mbc.02-07-0102.

25. Li Z, Wang C, Jiao X, Lu Y, Fu M, Quong AA, Dye C, Yang J, Dai M, Ju X, Zhang X, Li A, Burbelo P, Stanley ER, Pestell RG. Cyclin D1 regulates cellular migration through the inhibition of thrombospondin 1 and ROCK signalling. Mol Cell Biol 2006;26(11):4240-56.

26. Li Z, Jiao X, Wang C, Ju X, Lu Y, Yuan L, Lisanti MP, Katiyar S, Pestell RG. Cyclin D1 induction of cellular migration requires p27(KIP1). Cancer Res 2006;66(20):9986-94.

27. Shtutman M, Zhurinsky J, Simcha I, Albanese C, D'Amico M, Pestell $\mathrm{R}$, Ben-Ze'ev A. The cyclin D1 gene is a target of the beta-catenin/ LEF-1 pathway. Proc Natl Acad Sci U S A 1999;96(10):5522-7.

28. Chen LT, Xu SD, Xu H, Zhang JF, Ning JF, Wang SF. MicroRNA-378 is associated with non-small cell lung cancer brain metastasis by promoting cell migration, invasion and tumour angiogenesis. Med Oncol 2012;29(3):1673-80.

29. Hua Z, Lv Q, Ye W, Wong CK, Cai G, Gu D, Ji Y, Zhao C, Wang J, Yang BB, Zhang Y. MiRNA-directed regulation of VEGF and other angiogenic factors under hypoxia. PLoS One 2006;1:e116.

30. Arora S, Ranade AR, Tran NL, Nasser S, Sridhar S, Korn RL, Ross JT, Dhruv H, Foss KM, Sibenaller Z, Ryken T, Gotway MB, Kim S, Weiss GJ. MicroRNA-328 is associated with (non-small) cell lung cancer (NSCLC) brain metastasis and mediates NSCLC migration. Int J Cancer 2011;129(11):2621-31.

31. Liu X, Shi H, Liu B, Li J, Liu Y, Yu B. miR-330-3p controls cell proliferation by targeting early growth response 2 in non-small-cell lung cancer. Acta Biochim Biophys Sin 2015;47(6):431-40.

32. Unoki M, Nakamura Y. EGR2 induces apoptosis in various cancer cell lines by direct transactivation of BNIP3L and BAK. Oncogene 2003;22(14):2172-85.

33. Remon J, Alvarez-Berdugo D, Majem M, Moran T, Reguart N, Lianes P. miRNA-197 and miRNA-184 are associated with brain metastasis in EGFR-mutant lung cancers. Clin Transl Oncol 2015 Jul 22. [Epub ahead of print] doi: 10.1007/s12094-015-1347-2.

34. Zheng D, Haddadin S, Wang Y, Gu LQ, Perry MC, Freter CE, Wang MX. Plasma microRNAs as novel biomarkers for early detection of lung cancer. Int J Clin Exp Pathol 2011;4(6):575-868.

35. Du L, Schageman JJ, Subauste MC, Saber B, Hammond SM, Prudkin L, Wistuba II, Ji L, Roth JA, Minna JD, Pertsemlidis A. miR-93, miR-98, and miR-197 regulate expression of tumour suppressor gene FUS1. Mol Cancer Res 2009;7(8):1234-43.

36. Fiori ME, Barbini C, Haas TL, Marroncelli N, Patrizii M, Biffoni M, De Maria R. Antitumour effect of miR-197 targeting in p53 wild-type lung cancer. Cell Death Differ 2014;21(5):774-82.

37. Ji L, Roth JA. Tumour suppressor FUS1 signalling pathway. J Thorac Oncol 2008;3(4):327-30.

38. Liu Z, Mai C, Yang $H$, Zhen $Y$, Yu X, Hua S, Wu Q, Jiang Q, Zhang Y, 
Song X, Fang W. Candidate tumour suppressor CCDC19 regulates miR-184 direct targeting of C-Myc thereby suppressing cell growth in non-small cell lung cancers. J Cell Mol Med 2014;18(8):1667-79.

39. Wu GG, Li WH, He WG, Jiang N, Zhang GX, Chen W, Yang HF, Liu QL, Huang YN, Zhang L, Zhang T, Zeng XC. Mir-184 post-transcriptionally regulates SOX7 expression and promotes cell proliferation in human hepatocellular carcinoma. PLoS One 2014;9(2):e88796.

40. Hayano T, Garg M, Yin D, Sudo M, Kawamata N, Shi S, Chien W, Ding LW, Leong G, Mori S, Xie D, Tan P, Koeffler HP. SOX7 is down-regulated in lung cancer. J Exp Clin Cancer Res 2013;32:17.

41. Stovall DB, Cao P, Sui G. SOX7: from a developmental regulator to an emerging tumour suppressor. Histol Histopathol 2014;29(4):439459.

42. Guo L, Zhong D, Lau S, Liu X, Dong XY, Sun X, Yang VW, Vertino PM, Moreno CS, Varma V, Dong JT, Zhou W. Sox7 Is an independent checkpoint for beta-catenin function in prostate and colon epithelial cells. Mol Cancer Res 2008;6(9):1421-30.

43. Liu J, Wang $X$, Yang X, Liu Y, Shi Y, Ren J, Guleng B. miRNA423-5p regulates cell proliferation and invasion by targeting trefoil factor 1 in gastric cancer cells. Cancer Lett 2014;347(1):98-104.

44. Zhao C, Xu Y, Zhang Y, Tan W, Xue J, Yang Z, Zhang Y, Lu Y, Hu X. Downregulation of miR-145 contributes to lung adenocarcinoma cell growth to form brain metastases. Oncol Rep 2013;30(5):2027-34.

45. Zhang Y, Yang $X, W u ~ H$, Zhou W, Liu Z. MicroRNA-145 inhibits migration and invasion via inhibition of fascin 1 protein expression in non-small-cell lung cancer cells. Mol Med Rep 2015;12(4):6193-8.

46. Peraud A, Mondal S, Hawkins C, Mastronardi M, Bailey K, Rutka JT. Expression of fascin, an actin-bundling protein, in astrocytomas of varying grades. Brain Tumour Pathol 2003;20(2):53-8.

47. Zhang $\mathrm{Y}$, Lin Q. MicroRNA-145 inhibits migration and invasion by down-regulating FSCN1 in lung cancer. Int J Clin Exp Med 2015;8(6):8794-802.

48. Ye Z, Shen N, Weng Y, Li K, Hu L, Liao H, An J, Liu L, Lao S, Cai S. Low miR-145 silenced by DNA methylation promotes NSCLC cell proliferation, migration and invasion by targeting mucin 1. Cancer Biol Ther 2015;16(7):1071-9.

49. Jain S, Stroopinsky D, Yin L, Rosenblatt J, Alam M, Bhargava P, Clark RA, Kupper TS, Palmer K, Coll MD, Rajabi H, Pyzer A, Bar-Natan M, Luptakova K, Arnason J, Joyce R, Kufe D, Avigan D. Mucin 1 is a potential therapeutic target in cutaneous T-cell lymphoma. Blood 2015;126(3):354-62.

50. Cho WC, Chow AS, Au JS. MiR-145 inhibits cell proliferation of human lung adenocarcinoma by targeting EGFR and NUDT1. RNA Bio 2011;8(1):125-311

51. Mo JY, Maki H, Sekiguchi M. Hydrolytic elimination of a mutagenic nucleotide, 8-oxoGTP, by human 18-kilodalton protein: sanitization of nucleotide pool. Proc Natl Acad Sci USA 1992;89(22):11021-5.

52. Maki $\mathrm{H}$, Sekiguchi M. MutT protein specifically hydrolyzes a potent mutagenic substrate for DNA synthesis. Nat 1992;355(6357):273-5.

53. Kennedy $\mathrm{CH}$, Pass HI, Mitchell JB. Expression of human MutT homologue (hMTH1) protein in primary non-small cell lung carcinomas and histologically normal surrounding tissue. Free Radic Bio Med 2003;34(11):1447-57.

54. Okamoto K, Toyokuni S, Kim WJ, Ogawa O, Kakehi Y, Arao S, Hia $H$, Yoshida O. Overexpression of human mutT homologue gene messenge rRNA in renal-cell carcinoma: evidence of persistent oxidative stress in cencer. Int J Cancer 1996;65(4):437-41.

55. Wani G, Milo GE, D'Ambrosio SM. Enhanced expression of the 8-oxo-7,8-dihydrodeoxyguanosine triphosphatase gene in human breast tumour cells. Cancer Lett 1998;125(1-2):123-30.

56. Iida T, Furuta A, Kawashima M, Nishida J, Nakabeppu Y, Iwaki T. Accumulation of 8-oxo-2'- deoxyguanosine and increased expression of hMTH1 protein in brain tumours. Neuro Oncol 2001;3(2):7381.

57. Huber KV, Salah E, Radic B, Gridling M, Elkins JM, Stukalov A, Jemth AS, Göktürk C, Sanjiv K, Strömberg K, Pham T, Berglund UW, Colinge J,Bennett KL, Loizou Jl, Helleday T, Knapp S, Superti-Furga G. Stereospecific targeting of MTH1 by (S)-crizotinib as an anticancer strategy. Nature Apr 2 [Epub ahead of print] doi: 10.1038/nature13194.

58. Cheng CY, Hsieh HL, Sun CC, Lin CC, Luo SF, Yang CM. IL-1 beta induces urokinase-plasminogen activator expression and cell migration through PKC alpha, JNK1/2, and NF-kappaB in A549 cells. J Cel Physiol 2009;219(1):183-93.
59. Mignatti P, Rifkin DB. Biology and biochemistry of proteinases in tumour invasion. Physiol Rev 1993;73(1):161-95.

60. Hori K, Sen A, Artavanis-Tsakonas S. Notch signalling at a glance. J Cell Sci 2013;126(Pt 10):2135-40.

61. Grabher C, von Boehmer H, Look AT. Notch 1 activation in the molecular pathogenesis of T-cell acute lymphoblastic leukaemia. Nat Rev Cancer 2006;6(5):347-59.

62. Dang TP, Gazdar AF, Virmani AK, Sepetavec T, Hande KR, Minna JD, Roberts JR, Carbone DP. Chromosome 19 translocation, overexpression of Notch3, and human lung cancer. J Natl Cancer Inst 2000;92(16):1355-7.

63. Zhao M, Gao FH, Wang JY, Liu F, Yuan HH, Zhang WY, Jiang B. JAK2/ STAT3 signalling pathway activation mediates tumour angiogenesis by upregulation of VEGF and bFGF in non-small-cell lung cancer. Lung Cancer 2011;73(3):366-74.

64. Chen P, Zhu J, Liu DY, Li HY, Xu N, Hou M. Over-expression of survivin and VEGF in small-cell lung cancer may predict the poorer prognosis. Med Oncol 2014;31(1):775.

65. Shepard CR, Kassis J, Whaley DL, Kim HG, Wells A. PLC gamma contributes to metastasis of in situ-occurring mammary and prostate tumours. Oncogene 2007;26(21):3020-60.

66. Jones NP, Peak J, Brader S, Eccles SA, Katan M. PLCgamma1 is essential for early events in integrin signalling required for cell motility. $J$ Cell Sci 2005;118(Pt 12):2695-706.

67. Meng W, Ye Z, Cui R, Perry J, Dedousi-Huebner V, Huebner A, Wang Y, Li B, Volinia S, Nakanishi H, Kim T, Suh SS, Ayers LW, Ross P, Croce CM, Chakravarti A, Jin VX, Lautenschlaeger T. MicroRNA-31 predicts the presence of lymph node metastases and survival in patients with lung adenocarcinoma. Clin Cancer Res 2013;19(19):5423-33.

68. Johnen N, Francart ME, Thelen N, Cloes M, Thiry M. Evidence for a partial epithelial-mesenchymal transition in postnatal stages of rat auditory organ morphogenesis. Histochem Cell Biol 2012;138(3):477-88.

69. Yang Z, Garcia A, Xu S, Powell DR, Vertino PM, Singh S, Marcus Al. Withania somnifera root extract inhibits mammary cancer metastasis and epithelial to mesenchymal transition. PLoS One 2013;8(9):e75069.

70. Mendez MG, Kojima S, Goldman RD. Vimentin induces changes in cell shape, motility, and adhesion during the epithelial to mesenchymal transition. FASEB J 2010;24(6):1838-51.

71. Kang Y, Massagué J. Epithelial-mesenchymal transitions: twist in development and metastasis. Cell ;118(3):277-9.

72. Liu CHY, Lin HH, Tang MJ, Wang YK. Vimentin contributes to epithelial-mesenchymal transition cancer cell mechanics by mediating cytoskeletal orgatnization and focal adhesion maturation. Oncotarget 2015; 6(18): 15966-15983.

73. Lee JM, Dedhar S, Kalluri R, Thompson EW. The epithelial-mesenchymal transition: new insights in signalling, development, and disease. J Cell Biol 2006;172(7):973-81.

74. Snchez-Tilló E, Liu Y, de Barrios O, Siles L, Fanlo L, Cuatrecasas M, Darling DS, Dean DC, Castells A, Postigo A. EMT-activating transcription factors in cancer: beyond EMT and tumour invasiveness. Cell Mol Life Sci 2012;69(20):3429-56.

75. Kaufhold S, Bonavida B. Central role of Snail1 in the regulation of EMT and resistance in cancer: a target for therapeutic intervention. J Exp Clin Cancer Res 2014;33:62.

76. Pak MG, Lee CH, Lee WJ, Shin DH, Roh MS. Unique microRNAs in lung adenocarcinoma groups according to major TKI sensitive EGFR mutation status. Diagn Pathol 2015;10:99.

77. Sarver AL, Li L, Subramanian S. MicroRNA miR-183 functions as an oncogene by targeting the transcription factor EGR1 and promoting tumour cell migration. Cancer Res 2010;70(23):9570-80.

78. Baron V, Adamson ED, Calogero A, Ragona G, Mercola D. The transcription factor Egr1 is a direct regulator of multiple tumour suppressors including TGFbeta1, PTEN, p53, and fibronectin. Cancer Gene Ther 2006;13(2):115-24.

79. Yang J, Liu H, Wang H, Sun Y. Down-regulation of microRNA-181b is a potential prognostic marker of non-small cell lung cancer. Pathol Res Pract 2013;209(8):490-4.

80. Cui Y, Han Z, Hu Y, Song G, Hao C, Xia H, Ma X. MicroRNA-181b and microRNA-9 mediate arsenic-induced angiogenesis via NRP1. J Cell Physiol 2012;227(2):772-83.

81. Hong TM, Chen YL, Wu YY, Yuan A, Chao YC, Chung YC, Wu MH, Yang SC, Pan SH, Shih JY, Chan WK, Yang PC. Targeting neuro- 
pilin 1 as an antitumour strategy in lung cancer. Clin Cancer Res 2007;13(16):4759-68.

82. Gelfand MV, Hagan N, Tata A, Oh WJ, Lacoste B, Kang KT, Kopycinska J, Bischoff J, Wang JH, Gu C. Neuropilin-1 functions as a VEGFR2 coreceptor to guide developmental angiogenesis independent of ligand binding. Elife Sep 22 [Epub ahead of print] doi: 10.7554/ eLife.03720.

83. Lampropoulou A, Ruhrberg C. Neuropilin regulation of angiogenesis. Biochem Soc Trans 2014;42 (6) 1623-1628.

84. Ding M, Liu L, Hu C, Liu Y, Qiao Y, Jiang X. Expression of VEGFR2 and NRP-1 in non-small cell lung cancer and their clinical significance. Chin J Cancer Res 2014;26(6):669-77.

85. Sun Y, Ai X, Shen S, Lu S. NF-?B-mediated miR-124 suppresses metastasis of non-small-cell lung cancer by targeting MYO10. Oncotarget 2015;6(10):8244-54.

86. Courson DS, Cheney RE. Myosin-X and disease. Exp Cell Res 2015;334(1):10-5.

87. Schoumacher M, Goldman RD, Louvard D, Vignjevic DM. Actin, microtubules, and vimentin intermediate filaments cooperate for elongation of invadopodia. J Cell Biol 2010;189(3):541-56.

88. Hatziapostolou M, Polytarchou C, Aggelidou E, Drakaki A, Poultsides GA, Jaeger SA, Ogata H, Karin M, Struhl K, Hadzopoulou-Cladaras M, Iliopoulos D. An HNF4a-miRNA inflammatory feedback circuit regulates hepatocellular oncogenesis. Cell 2011;147(6):1233-47.

89. Xie C, Han Y, Liu Y, Han L, Liu J. miRNA-124 down-regulates SOX8 expression and suppresses cell proliferation in non-small cell lung cancer. Int J Clin Exp Pathol 2014;7(11):7518-264.

90. Zhang S, Zhu C, Zhu L, Liu H, Liu S, Zhao N, Wu J, Huang X, Zhang Y, Jin J, Ji T, Ding X. Oncogenicity of the transcription factor SOX8 in hepatocellular carcinoma. Med Oncol 2014;31(4):918.

91. Zhu D, Chen H, Yang X, Chen W, Wang L, Xu J, Yu L. Decreased microRNA-224 and its clinical significance in non-small cell lung cancer patients. Diagn Pathol 2014;9:198.

92. Cui R, Meng W, Sun HL, Kim T, Ye Z, Fassan M, Jeon YJ, Li B, Vicentini C, Peng Y, Lee TJ, Luo Z, Liu L, Xu D, Tili E, Jin V, Middleton J, Chakravarti A, Lautenschlaeger T, Croce CM. MicroRNA-224 promotes tumour progression in nonsmall cell lung cancer. Proc Natl Acad Sci U S A 2015;112(31):E4288-97.

93. Zhou J, Hu X, Xiong X, Liu X, Liu Y, Ren K, Jiang T, Hu X, Zhang J. Cloning of two rat PDIP1 related genes and their interactions with proliferating cell nuclear antigen. J Exp Zool A Comp Exp Biol 2005;303(3):227-40.

94. Blobe GC, Schiemann WP, Lodish HF. Role of transforming growth factor beta in human disease. N Engl J Med 2000;342(18):1350-8.

95. Anumanthan G, Halder SK, Osada H, Takahashi T, Massion PP, Carbone DP, Datta PK. Restoration of TGF-beta signalling reduces tumourigenicity in human lung cancer cells. Br J Cancer 2005;93(10):1157-67.

96. Cui $R_{\mu}$ Kim T, Fassan $M_{\mu}$ Meng $W_{\text {, Sun }} H L$, Jeon YJ, Vicentini C, Til E, Peng Y, Scarpa A, Liang G, Zhang YK, Chakravarti A, Croce CM MicroRNA-224 is implicated in lung cancer pathogenesis through targeting caspase-3 and caspase-7. Oncotarget 2015;6(26):21802 15.

97. Li J, Yuan J. Caspases in apoptosis and beyond. Oncogene 2008;27(48):6194-206.

98. Hirata H, Takahashi A, Kobayashi S, Yonehara S, Sawai H, Okazaki T, Yamamoto K, Sasada M. Caspases are activated in a branched protease cascade and control distinct downstream processes in Fasinduced apoptosis. J Exp Med 1998;187(4):587-600.

99. Slee EA, Harte MT, Kluck RM, Wolf BB, Casiano CA, Newmeyer DD, Wang HG, Reed JC, Nicholson DW, Alnemri ES, Green DR, Martin SJ. Ordering the cytochrome c-initiated caspase cascade: hierarchical activation of caspases-2, $-3,-6,-7,-8$, and -10 in a caspase-9-dependent manner. J Cell Biol 1999;144(2):281-92.

100. Ge H, Li B, Hu WX, Li RJ, Jin H, Gao MM, Ding CM. MicroRNA-148b is down-regulated in non-small cell lung cancer and associated with poor survival. Int J Clin Exp Pathol 2015;8(1):800-55.

101. Yang JS, Li BJ, Lu HW, Chen Y, Lu C, Zhu RX, Liu SH, Yi QT, Li J, Song CH. Serum miR-152, miR-148a, miR-148b, and miR-21 as novel biomarkers in non-small cell lung cancer screening. Tumour Biol 2015;36(4):3035-42.

102. Li J, Song Y, Wang Y, Luo J, Yu W. MicroRNA-148a suppresses epithelial-to-mesenchymal transition by targeting ROCK1 in non-small cell lung cancer cells. Mol Cell Biochem 2013;380(1-2):277-82.
103. Liu GL, Liu X, Lv XB, Wang XP, Fang XS, Sang Y. miR-148b functions as a tumour suppressor in non-small cell lung cancer by targeting carcinoembryonic antigen (CEA). Int J Clin Exp Med 2014;7(8):199094.

104. Kuespert $K$, Pils S, Hauck CR. CEACAMs: their role in physiology and pathophysiology. Curr Opin Cell Biol 2006;18(5):565-717.

105. Su Y, Wang Y, Zhou H, Lei L, Xu L. MicroRNA-152 targets ADAM17 to suppress NSCLC progression. FEBS Lett 2014;588(10):1983-8.

106. Cheng Z, Ma R, Tan W, Zhang L. MiR-152 suppresses the proliferation and invasion of NSCLC cells by inhibiting FGF2. Exp Mol Med 2014;46:e112.

107. Wan L, Zhu L, Xu J, Lu B, Yang Y, Liu F, Wang Z. MicroRNA-409-3p functions as a tumour suppressor in human lung adenocarcinoma by targeting c-Met. Cell Physiol Biochem 2014;34(4):1273-90.

108. Porter AC, Vaillancourt RR. Tyrosine kinase receptor-activated signal transduction pathways which lead to oncogenesis. Oncogene 1998:17(11 Reviews):1343-52.

109. Lowery FJ, Yu D. Growth factor signalling in metastasis: current understanding and future opportunities. Cancer Metastasis Rev 2012;31(3-4):479-91.

110. Grzelakowska-Sztabert B, Dudkowska M. Paradoxical action of growth factors: antiproliferative and proapoptotic signalling by HGF/c-MET. Growth Factors 2011;29(4):105-18.

111. Organ SL, Tsao MS. An overview of the c-MET signalling pathway. Ther Adv Med Oncol 2011;3(1 Suppl):S7-S19.

112. Yu T, Li J, Yan M, Liu L, Lin H, Zhao F, Sun L, Zhang Y, Cui Y, Zhang F, Li J, He X, Yao M. MicroRNA-193a-3p and -5p suppress the metastasis of human non-small-cell lung cancer by downregulating the ERBB4/PIK3R3/mTOR/S6K2 signalling pathway. Oncogene 2015;34(4):413-23.

113. Anastasi $S$, Lamberti $D$, Alemà $S$, Segatto $O$. Regulation of the ErbB network by the MIG6 feedback loop in physiology, tumour suppression and responses to oncogene-targeted therapeutics. Semin Cell Dev Biol 2015 Oct 9. [Epub ahead of print] doi:10.1016/j. semcdb.2015.10.001.

114. Fumarola C, Bonelli MA, Petronini PG, Alfieri RR. Targeting PI3K/AKT/ mTOR pathway in non small cell lung cancer. Biochem Pharmacol 2014;90(3):197-207.

115. Scrima M, De Marco C, Fabiani F, Franco R, Pirozzi G, Rocco G, Ravo M, Weisz A, Zoppoli P, Ceccarelli M, Botti G, Malanga D, Viglietto G. Signalling networks associated with AKT activation in non-small cell lung cancer (NSCLC): new insights on the role of phosphatydilinositol-3 kinase. PLoS One 2012;7(2):e30427.

116. He D, Wang J, Zhang C, Shan B, Deng X, Li B, Zhou Y, Chen W, Hong J, Gao Y, Chen Z, Duan C. Down-regulation of miR-675-5p contributes to tumour progression and development by targeting protumourigenic GPR55 in non-small cell lung cancer. Mol Cancer 2015;14:73.

117. Li T, Song T, Ni L, Yang G, Song X, Wu L, Liu B, Liu C. The p-ERK-p-cJun-cyclinD1 pathway is involved in proliferation of smooth muscle cells after exposure to cigarette smoke extract. Biochem Biophys Res Commun 2014;453(3):316-20.

118. Gautschi O, Ratschiller D, Gugger M, Betticher DC, Heighway J. Cyclin D1 in non-small cell lung cancer: a key driver of malignant transformation. Lung Cancer 2007;55(1):1-147.

119. Hinz M, Krappmann D, Eichten A, Heder A, Scheidereit C, Strauss M. NF-kappaB function in growth control: regulation of cyclin D1 expression and G0/G1-to-S-phase transition. Mol Cell Biol 1999;19(4):2690-8.

120. Salhia B, Tran NL, Symons M, Winkles JA, Rutka JT, Berens ME. Molecular pathways triggering glioma cell invasion. Expert Rev Mol Diagn 2006;6(4):613-26.

121. Stamenkovic I. Matrix metalloproteinases in tumour invasion and metastasis. Semin Cancer Biol 2000;10(6):415-33.

122. Gialeli $C$, Theocharis AD, Karamanos NK. Roles of matrix metalloproteinases in cancer progression and their pharmacological targeting. FEBS J Nov 19 [Epub ahead of print] doi: 10.1111/j.17424658.2010.07919.x.

123. Deryugina El, Quigley JP. Matrix metalloproteinases and tumour metastasis. Cancer Metastasis Rev 2006;25(1):9-34.

124. Pei J, Lou Y, Zhong R, Han B. MMP9 activation triggered by epidermal growth factor induced FoxO1 nuclear exclusion in non-small cell lung cancer. Tumour Biol 2014;35(7):6673-8.

125. Jian H, Zhao Y, Liu B, Lu S. SEMA4b inhibits MMP9 to prevent metas- 
tasis of non-small cell lung cancer. Tumour Biol 2014;35(11):110516.

126. Wang H, Guan X, Tu Y, Zheng S, Long J, Li S, Qi C, Xie X, Zhang $\mathrm{H}$, Zhang Y. MicroRNA-29b attenuates non-small cell lung cancer metastasis by targeting matrix metalloproteinase 2 and PTEN. J Exp Clin Cancer Res 2015;34:59.

127. Song MS, Salmena L, Pandolfi PP. The functions and regulation of the PTEN tumour suppressor. Nat Rev Mol Cell Biol 2012;13(5):283 96.

128. de Assis LV, Isoldi MC. The function, mechanisms, and role of the genes PTEN and TP53 and the effects of asbestos in the development of malignant mesothelioma: a review focused on the genes' molecular mechanisms. Tumour Biol 2014;35(2):889-901.

129. Tang R, Zhong T, Dang Y, Zhang X, Li P, Chen G. Association between downexpression of MiR-203 and poor prognosis in non-small cel lung cancer patients. Clin Transl Oncol 2015 Aug 26. [Epub ahead of print] doi: 10.1007/s12094-015-1377-9.

130. Wang $N$, Liang $H$, Zhou $Y$, Wang $C$, Zhang S, Pan $Y$, Wang $Y$, Yan $X$ Zhang J, Zhang CY, Zen K, Li D, Chen X. miR-203 suppresses the proliferation and migration and promotes the apoptosis of lung cancer cells by targeting SRC. PLoS One 2014;9(8):e105570.

131. O'Neill AK, Gallegos LL, Justilien V, Garcia EL, Leitges M, Fields AP, Hall RA, Newton AC. Protein kinase Ca promotes cell migration through a PDZ-dependent interaction with its novel substrate discs large homolog 1 (DLG1). J Biol Chem 2011;286(50):43559-68.

132. Jin J, Deng J, Wang F, Xia X, Qiu T, Lu W, Li X, Zhang H, Gu X, Liu Y, Cao W, Shao W. The expression and function of microRNA-203 in lung cancer. Tumour Biol 2013;34(1):349-57.

133. McKenzie JA, Grossman D. Role of the apoptotic and mitotic regulator survivin in melanoma. Anticancer Res 2012;32(2):397-404.

134. Saini S, Majid S, Yamamura S, Tabatabai L, Suh SO, Shahryari V Chen Y, Deng G, Tanaka Y, Dahiya R. Regulatory Role of mir-203 in Prostate Cancer Progression and Metastasis. Clin Cancer Res 2011;17(16):5287-98.

135. Wang $N$, Liang $H$, Zhou $Y$, Wang $C$, Zhang $S$, Pan $Y$, Wang $Y$, Yan $X$, Zhang J, Zhang CY, Zen K, Li D, Chen X. miR-203 suppresses the proliferation and migration and promotes the apoptosis of lung cancer cells by targeting SRC. PLoS One 2014;9(8):e105570.

136. Ren P, Gong F, Zhang Y, Jiang J, Zhang H. MicroRNA-92a promotes growth, metastasis, and chemoresistance in non-small cell lung cancer cells by targeting PTEN. Tumour Biol 2015 Oct 02. [Epub ahead of print] doi: 10.1007/s13277-015-4150-3.

137. Zhang J, Han L, Ge Y, Zhou X, Zhang A, Zhang C, Zhong Y, You Y, Pu P, Kang C. miR-221/222 promote malignant progression of glioma through activation of the Akt pathway. Int J Oncol 2010;36(4):91320.

138. Chen S, Li P, Yang R, Cheng R, Zhang F, Wang Y, Chen X, Sun Q, Zang W, Du Y, Zhao G, Zhang G. microRNA-30b inhibits cell invasion and migration through targeting collagen triple helix repeat containing 1 in non-small cell lung cancer. Cancer Cell Int 2015;15:85.

139. Pesta M, Kulda V, Kucera R, Pesek M, Vrzalova J, Liska V, Pecen L, Treska V, Safranek J, Prazakova M, Vycital O, Bruha J, Holubec L, Topolcan O. Prognostic significance of TIMP-1 in non-small cell lung cancer. Anticancer Res 2011;31(11):4031-8.

140. Ke Z, He W, Lai Y, Guo X, Chen S, Li S, Wang Y, Wang L. Overexpression of collagen triple helix repeat containing 1 (CTHRC1) is associated with tumour aggressiveness and poor prognosis in human nonsmall cell lung cancer. Oncotarget 2014;5(19):9410-24.

141. Yan A, Yang C, Chen Z, Li C, Cai L. MiR-761 Promotes Progression and Metastasis of Non-Small Cell Lung Cancer by Targeting ING4 and TIMP2. Cell Physiol Biochem 2015;37(1):55-66.

142. Bourboulia D, Han H, Jensen-Taubman S, Gavil N, Isaac B, Wei B, Neckers L, Stetler-Stevenson WG. TIMP-2 modulates cancer cell transcriptional profile and enhances E-cadherin/beta-catenin complex expression in A549 lung cancer cells. Oncotarget 2013;4(1):163-73.

143. Xie Y, Zhang H, Sheng W, Xiang J, Ye Z, Yang J. Adenovirus-mediated ING4 expression suppresses lung carcinoma cell growth via induction of cell cycle alteration and apoptosis and inhibition of tumour invasion and angiogenesis. Cancer Lett 2008;271(1):105-16.

144. Garkavtsev I, Kozin SV, Chernova O, Xu L, Winkler F, Brown E, Barnett GH, Jain RK. The candidate tumour suppressor protein ING4 regulates brain tumour growth and angiogenesis. Nature 2004;428(6980):328-32.
145. Li Y, Jiang Q, Xia N, Yang H, Hu C. Decreased expression of microRNA-375 in nonsmall cell lung cancer and its clinical significance. J Int Med Res 2012;40(5):1662-9.

146. Yu H, Jiang L, Sun C, Guo L, Lin M, Huang J, Zhu L. Decreased circulating miR-375: A potential biomarker for patients with nonsmall-cell lung cancer. Gene 2013 Jan 15 [Epub ahead of print] doi: 10.1016/j.gene.2013.10.024.

147. Kong KL, Kwong DL, Chan TH, Law SY, Chen L, Li Y, Qin YR, Guan $X Y$. MicroRNA-375 inhibits tumour growth and metastasis in oesophageal squamous cell carcinoma through repressing insulinlike growth factor 1 receptor. Gut 2012;61(1):33-42.

148. Hu G, Wei Y, Kang Y. The multifaceted role of MTDH/AEG-1 in cancer progression. Clin Cancer Res 2009;15(18):5615-20.

149. He W, He S, Wang Z, Shen H, Fang W, Zhang Y, Qian W, Lin M, Yuan J, Wang J, Huang W, Wang L, Ke Z. Astrocyte elevated gene-1 (AEG-1) induces epithelial-mesenchymal transition in lung cancer through activating Wnt/ $\beta$-catenin signalling. BMC Cancer 2015;15:107.

150. Lan D, Zhang X, He R, Tang R, Li P, He Q, Chen G. MiR-133a is downregulated in non-small cell lung cancer: a study of clinical significance. Eur J Med Res 2015;20:50.

151. Wang LK, Hsiao TH, Hong TM, Chen HY, Kao SH, Wang WL, Yu SL, Lin CW, Yang PC. MicroRNA-133a suppresses multiple oncogenic membrane receptors and cell invasion in non-small cell lung carcinoma. PLoS One 2014;9(5):e96765.

152. Kim JS, Kim ES, Liu D, Lee JJ, Solis L, Behrens C, Lippman SM, Hong WK, Wistuba II, Lee HY. Prognostic implications of tumoural expression of insulin like growth factors 1 and 2 in patients with nonsmall-cell lung cancer. Clin Lung Cancer 2014;15(3):213-21.

153. Heldin $\mathrm{CH}$, Miyazono $\mathrm{K}$, ten Dijke P. TGF-beta signalling from cell membrane to nucleus through SMAD proteins. Nature 1997;390(6659):465-71.

154. Park C, Kim WS, Choi Y, Kim H, Park K. Effects of transforming growth factor beta (TGF-beta) receptor on lung carcinogenesis. Lung Cancer 2002;38(2):143-7.

155. Wang D, Kanuma T, Mizunuma H, Takama F, Ibuki Y, Wake N, Mogi A, Shitara Y, Takenoshita S. Analysis of specific gene mutations in the transforming growth factor-beta signal transduction pathway in human ovarian cancer. Cancer Res 2000;60(16):4507-12.

156. Im YH, Kim HT, Kim IY, Factor VM, Hahm KB, Anzano M, Jang JJ, Flanders K, Haines DC, Thorgeirsson SS, Sizeland A, Kim SJ. Heterozygous mice for the transforming growth factor-beta type II receptor gene have increased susceptibility to hepatocellular carcinogenesis. Cancer Res 2001;61(18):6665-8.

157. Lei Z, Liu RY, Zhao J, Liu Z, Jiang X, You W, Chen XF, Liu X, Zhang K, Pasche B, Zhang HT.TGFBR1 haplotypes and risk of non-small-cell lung cancer. Cancer Res 2009;69(17):7046-52.

158. Oda K, Matsuoka Y, Funahashi A, Kitano H. A comprehensive pathway map of epidermal growth factor receptor signalling. Mol Syst Biol 2005;1:20055.

159. Holbro T, Civenni G, Hynes NE. The ErbB receptors and their role in cancer progression. Exp Cell Res 2003;284(1):99-110.

160. Zhang Z, Stiegler AL, Boggon TJ, Kobayashi S, Halmos B. EGFRmutated lung cancer: a paradigm of molecular oncology. Oncotarget 2010;1(7):497-514.

161. Guo Q, Zhang H, Zhang L, He Y, Weng S, Dong Z, Wang J, Zhang $P$, Nao R. MicroRNA-21 regulates non-small cell lung cancer cell proliferation by affecting cell apoptosis via COX-19. Int J Clin Exp Med 2015;8(6):8835-415.

162. Leary SC, Cobine PA, Nishimura T, Verdijk RM, de Krijger R, de Coo R, Tarnopolsky MA, Winge DR, Shoubridge EA. COX19 mediates the transduction of a mitochondrial redox signal from SCO1 that regulates ATP7A-mediated cellular copper efflux. Mol Biol Cell 2013;24(6):683-91.

163. Leadsham JE, Sanders G, Giannaki S, Bastow EL, Hutton R, Naeim WR, Breitenbach M, Gourlay CW. Loss of cytochrome c oxidase promotes RAS-dependent ROS production from the ER resident NADPH oxidase, Yno1p, in yeast. Cell Metab 2013;18(2):279-86.

164. Hu H, Li S, Liu J, Ni B. MicroRNA-193b modulates proliferation, migration, and invasion of non-small cell lung cancer cells. Acta Biochim Biophys Sin (Shanghai) 2012;44(5):424-30.

165. Nigg EA. Cyclin-dependent protein kinases: key regulators of the eukaryotic cell cycle. Bioassays 1995;17(6):471-80.

166. Knudsen KE, Diehl JA, Haiman CA, Knudsen ES. Cyclin D1: 
polymorphism, aberrant splicing and cancer risk. Oncogene 2006;25(11):1620-8

167. Klein EA, Assoian RK. Transcriptional regulation of the cyclin D1 gene at a glance. J Cell Sci 2008;121(Pt 23):3853-7.

168. Chapman HA. Plasminogen activators, integrins, and the coordinated regulation of cell adhesion and migration. Curr Opin Cell Biol 1997;9(5):714-24.

169. Sidenius N, Blasi F. The urokinase plasminogen activator system in cancer: recent advances and implication for prognosis and therapy. Cancer Metastasis Rev 2003:22(2-3):205-22.

170. Savita U, Karunagaran D. MicroRNA-106b-25 cluster targets $\beta$-TRCP2, increases the expression of Snail and enhances cell migration and invasion in $\mathrm{H} 1299$ (non small cell lung cancer) cells. Biochem Biophys Res Commun 2013;434(4):841-7.

171. Frescas D, Pagano M. Deregulated proteolysis by the F-box proteins SKP2 and beta-TrCP: tipping the scales of cancer. Nat Rev Cancer 2008;8(6):438-49.

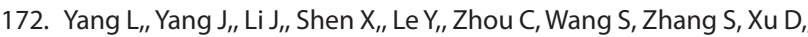
Gong Z,. MircoRNA-33a inhibits epithelial-to-mesenchymal transition and metastasis and could be a prognostic marker in non-smal cell lung cancer. Sci Rep 2015;5:13677.

173. Qin Q, Xu Y, He T, Qin C, Xu J. Normal and disease-related biological functions of Twist 1 and underlying molecular mechanisms. Cell Res 2012;22(1):90-106.

174. Higashijima J, Kurita N, Miyatani T, Yoshikawa K, Morimoto S, Nishioka M, Iwata T, Shimada M. Expression of histone deacetylase 1 and metastasis-associated protein 1 as prognostic factors in colon cancer. Oncol Rep 2011;26(2):343-8.

175. Zhang H, Zhu X, Li N, Li D, Sha Z, Zheng X, Wang H. miR-125a-3p targets MTA1 to suppress NSCLC cell proliferation, migration, and invasion. Acta Biochim Biophys Sin (Shanghai) 2015;47(7):496-503.

176. Sasaki H, Moriyama S, Nakashima Y, Kobayashi Y, Yukiue H, Kaji M, Fukai I, Kiriyama M, Yamakawa Y, Fujii Y. Expression of the MTA1 mRNA in advanced lung cancer. Lung Cancer 2002;35(2):149-54.

177. Li DQ, Pakala SB, Nair SS, Eswaran J, Kumar R. Metastasis-associated protein 1 /nucleosome remodelling and histone deacetylase complex in cancer. Cancer Res 2012;72(2):387-94.

178. Wang W, Wu X, Tian Y. Crosstalk of AP4 and TGF $\beta$ receptor signalling in NSCLC. Tumour Biol 2015;36(1):447-52.

179. Gong H, Han S, Yao H, Zhao H, Wang Y. AP 4 predicts poor prognosis in non small cell lung cancer. Mol Med Rep 2014;10(1):336-40.

180. Gao F, Wang T, Zhang Z, Wang R, Guo Y, Liu J. Regulation of activating protein-4-associated metastases of non-small cell lung cancer cells by miR-144. Tumour Biol 2015 Aug 08 [Epub ahead of print] doi: 10.1007/s13277-015-3866-4.

181. Yang T, Chen T, LiY, Gao L, Zhang S, Wang T, Chen M. Downregulation of miR-25 modulates non-small cell lung cancer cells by targeting CDC42. Tumour Biol 2015;36(3):1903-11.

182. Fidyk N, Wang JB, Cerione RA. Influencing cellular transformation by modulating the rates of GTP hydrolysis by Cdc42. Biochemistry 2006;45(25):7750-62.

183. Zhang JY, Zhang D, Wang EH. Overexpression of small GTPases directly correlates with expression of $\mathrm{d}$-catenin and their coexpression predicts a poor clinical outcome in nonsmall cell lung cancer. Mol Carcinog 2013;52(5):338-47.

184. Li D, Yang Y, Zhu G, Liu X, Zhao M, Li X, Yang Q. MicroRNA-410 promotes cell proliferation by targeting BRD7 in non-small cell lung cancer. FEBS Lett 2015:589(17):2218-23.

185. Park YA, Lee JW, Kim HS, Lee YY, Kim TJ, Choi CH, Choi JJ, Jeon HK, Cho YJ, Ryu JY, Kim BG, Bae DS. Tumour suppressive effects of bromodomain-containing protein 7 (BRD7) in epithelial ovarian carcinoma. Clin Cancer Res 2014;20(3):565-75.

186. Wu WJ, Hu KS, Chen DL, Zeng ZL, Luo HY, Wang F, Wang DS, Wang $\mathrm{ZQ}$, He F, Xu RH. Prognostic relevance of BRD7 expression in colorectal carcinoma. Eur J Clin Invest 2013;43(2):131-40.

187. Hu K, Liao D, Wu W, Han AJ, Shi HJ, Wang F, Wang X, Zhong L, Duan T, Wu Y, Cao J, Tang J, Sang Y, Wang L, Lv X, Xu S, Zhang RH, Deng WG, Li SP, Zeng YX, Kang T. Targeting the anaphase-promoting complex/cyclosome (APC/C)- bromodomain containing 7 (BRD7) pathway for human osteosarcoma. Oncotarget 2014;5(10):3088100.

188. Chen L, Yu F. [Expression and clinical significance of bromodomaincontaining protein 7 in non-small cell lung cancer]. Zhongguo Fei Ai Za Zhi 2011;14(10):830-4.

189. Drost J, Mantovani F, Tocco F, Elkon R, Comel A, Holstege H, Kerkhoven R, Jonkers J, Voorhoeve PM, Agami R, Del Sal G. BRD7 is a candidate tumour suppressor gene required for $\mathrm{p} 53$ function. Nat Cell Biol 2010;12(4):380-9.

190. Peng C, Liu HY, Zhou M, Zhang LM, Li XL, Shen SR, Li GY. BRD7 suppresses the growth of Nasopharyngeal Carcinoma cells (HNE1) through negatively regulating beta-catenin and ERK pathways. Mo Cell Biochem 2007;303(1-2):141-96.

191. Chiu YH, Lee JY, Cantley LC. BRD7, a tumour suppressor, interacts with p85a and regulates PI3K activity. Mol Cell 2014;54(1):193-202. 